\title{
The CDS-bond Basis: Negativity Persistence and Limits to Arbitrage*
}

\author{
Sahar Guesmi ${ }^{1}$ \\ Ramzi Ben-Abdallah² \\ Michèle Breton ${ }^{3}$ \\ Georges Dionne ${ }^{4}$
}

4 November 2019

\begin{abstract}
We reinvestigate the CDS-bond basis negativity puzzle after the financial crisis. This puzzle is defined as the unexpected persistence of the dislocation between bond and derivative credit markets. We show that the first two moments of the basis are described by three distinct Markov regimes identified with periods related to the 2008 financial crisis. We observe that the post-crisis regime differs significantly from the crisis and the pre-crisis regimes. We then explore the cross-sectional variation of the CDS-bond basis in each regime. Using a model with several limit-to-arbitrage factors, we validate that the negative basis can be explained by liquidity risk in both the bond and CDS markets, together with counterparty risk, collateral quality, and funding constraints. Finally, we propose a model to empirically affirm that the basis negativity persistence during the post-crisis period is mainly related to a significant decrease in basis arbitrage activity, which is partly explained by the post-crisis regulatory reforms.
\end{abstract}

JEL Classification: G12; G13; G14; G18; G28.

Keywords: CDS-bond basis, Markov regime, arbitrage, liquidity, financial crisis, Basel regulation, DoddFrank Act.

* Research supported by NSERC Canada, SSHRC Canada and the Canadian Derivatives Institute. It has been presented to the FMA 2009 conference.

${ }^{1}$ HEC Montréal, Canada. sahar.guesmi@hec.ca.

${ }^{2}$ UQAM School of Management, Canada. ben_abdallah.ramzi@uqam.ca.

${ }^{3}$ HEC Montréal, Canada. michele.breton@hec.ca.

${ }^{4}$ Canada Research Chair in Risk Management, HEC Montréal, Canada. georges.dionne@hec.ca. 


\section{Introduction}

In recent decades, credit default swaps (CDS) have become a significant component of financial markets. CDSs are among the most liquid derivatives traded during this period. A CDS and its protected corporate bond are considered reliable gauges of a given obligor's default risk. Consequently, a strong statistical relationship exists between the valuation of these two financial instruments. The CDS-bond basis is the common way to quantify this relationship. It is defined as the difference between the CDS premium and the default spread of a corporate bond with the same maturity.

In a frictionless market, a corporate bond and its CDS protection are expected to be priced equally for bond default risk, such that the basis should not differ significantly from zero. However, market conditions may cause the CDS-bond link to deviate from parity and the basis to become non-null, raising the possibility of profits from arbitrage activities. Before the financial crisis, arbitrageurs took advantage of this pricing mismatch, which made the spread difference between the bond (cash) and derivative markets quickly return to its equilibrium value at zero.

When financial markets were hit by the financial crisis of 2008 , the well-established connection between the CDS premium and the bond spread broke down significantly, and the basis became strongly negative. This departure from equilibrium persisted over several months and across several firms belonging to different industries and rating classes. The consequences of this situation were severe for many market participants, such as Citadel, Deutsche Bank, and Merrill Lynch, which wrongly assumed that the observed negative CDS-bond basis was a regular, short-lived and riskless arbitrage opportunity. Although the basis tightened after the financial crisis, it did not return to its pre-crisis level, and has remained persistently and conspicuously negative (Adrian, Fleming and Shachar, 2017). Given the puzzling basis fluctuations observed during the last decade, the link between the corporate bond and the CDS has become an intriguing research subject that has been little investigated in the literature.

The aim of this paper is to explain the persistent negativity of the CDS-bond basis after the financial crisis. We contend that this persistence is due to a dysfunction in the habitual arbitrage mechanism, accentuated by market regulation. Our argumentation follows three steps. First we show that the evolution of the basis during the period 01-2006 to 09-2014 exhibits three distinct Markov regimes, and that the post-crisis regime differs from the regimes that prevailed before and during the onset of the financial crisis. We then explore the cross-sectional variations of the CDS-bond basis in each regime, affirming that the price inconsistencies largely reflect the various risks and costs associated with the basis arbitrage activity. We 
show that these risks and costs changed significantly during and after the financial crisis. The main empirical factors are bond and CDS illiquidity, CDS counterparty risk, deterioration of bond-collateral quality, and funding constraints during the two periods. For robustness, we also consider three distinct calendar periods (before, during, and after the recent financial crisis) and confirm that the impact of risk and cost factors on basis trading is most pronounced during the crisis subperiod (01/07/2007-31/03/2009) but is also observed after this period. In the third step, we provide empirical evidence of the decrease in arbitrage activity following changes in the regulatory framework after the 2007-2009 financial crisis and relate the decrease to the Basel III and Dodd-Franck Act post-crisis regulatory reforms. This is done by tracing, through different periods, the effect of arbitrage on two major aspects of the corporate bond market: transaction volume and pricing.

Despite the abundant literature on CDS-bond basis fluctuations (Bai and Collin-Dufresne, 2019; Kim, 2017; Arakelyan and Serrano, 2016), our paper is the only contribution explaining these variations in an endogenous risk-return framework. Our first contribution is to test that the data studied come from possible distinct states. Given that these states are not observable, we estimate a Hidden Markov Model (HMM) to endogenously identify negative basis regimes from normal or zero-basis regimes.

Our second contribution to the literature is to model differently how liquidity risk factors affect the basis in the detected regimes. We are the first to consider both bond and CDS relative illiquidity as potential determinants of the basis. Recently, it was shown that the CDS-bond basis is not limited to default risk, but rather can integrate an illiquidity basis component (Kim 2017). Moreover, bond liquidity risk was mostly reduced to a single dimension. We opt for an aggregate measure to capture the multidimensional aspect of liquidity risk, consistent with Dick-Nielsen, Feldhutter and Lando (2012), and Dionne and Maalaoui (2013). Moreover, while most of the literature considers bond illiquidity as a sufficient indicator of liquidity risk in this market (Kryukova and Copeland, 2015; Longstaff et al., 2005), recent empirical evidence (Arakelyan and Serrano, 2016) shows that CDS spreads may also contain a relevant liquidity premium. We incorporate all these liquidity risks in the factors that may explain the negative persistence of the basis.

The third and most innovative contribution is our detailed analysis of basis negative persistence in the post-crisis period. Our paper is the first to explicitly isolate, from a regression analysis, the factors explaining why the basis did not return to its pre-crisis level after the financial markets recovered. We show that this phenomenon is explained by a significant deterioration in investors' involvement in basis 
arbitrage activity. This result supports the growing body of literature on the adverse impact of the new post-crisis regulatory framework on financial markets and on their major participants, including primary dealers (Anderson and Stulz, 2017; Dick-Nielsen and Rossi, 2017; Bao, O'Hara and Zhou, 2018; Boyarchenko, Gupta, Steele and Yen, 2016). More specifically, Boyarchenko et al. (2016) argue that the new leverage ratio constraint on banks makes their basis trading more expensive. Our empirical results suggest a decrease in arbitrage activity after the financial crisis. They further contribute to limits-toarbitrage research by providing two new proxies for non-observable arbitrage activity using a methodology to infer arbitrage.

Our results compare favorably to those in the literature, and notably to those of the seminal paper of Bai and Collin-Dufresne (2019), in explaining the variation of the basis across several calendar periods. Our contribution differs by offering an endogenous division of the basis variation during the 2006-2014 period by using a Markov switching model. We show that the explanatory factors of the basis variation during the three detected regimes remain highly effective. We propose a formal test of the limit to arbitrage explanation related to the persistent negative basis during the post-crisis period. Finally, we show empirically how the post-crisis changes in financial market regulations dampened arbitrage activities.

The rest of the paper is organized as follows. Section 2 reviews the literature pertaining to the CDS-bond basis. Section 3 reviews the link between the CDS and bond markets and describes the risks inherent to negative basis trading. Section 4 provides details on the empirical methodology used to explore the basis cross-sectional variation and to explain negativity persistence during the post-crisis period. Our dataset is presented in Section 5, and our empirical results are discussed in Section 6. Section 7 concludes the paper.

\section{Literature review}

Our research is mainly related to the literature on the empirical interplay between the bond and CDS markets. Contributions to this topic and research interests can be classified according to three consecutive periods: before, during and after the 2008 financial crisis. Initially, research focused on finding empirical evidence for the theoretical parity relationship and on explaining the fact that the basis was generally slightly positive. During the crisis, the link between the CDS and bond markets was clearly violated, which

made researchers shift their interest to exploring the determinants of a negative basis. Despite a remarkable change in the basis levels compared with the pre-crisis period, research on the post-crisis period is rather scant. 
Long before the financial crisis, Duffie (1999) argued that, under reasonable assumptions, there is a theoretical equivalence between the CDS premium and the floating-rate spread of a corporate bond with similar maturity, issued by the same entity. This theoretical link was empirically verified by Blanco, Brennan and Marsh (2005), who document a stable equilibrium equating credit prices on cash and synthetic markets for most of the entities considered. However, these authors find that this relationship does not hold in the short run, for a limited number of companies where the CDS spread is an upper bound for the credit-risk price, corresponding to a slightly positive basis. This is partly explained by the cheapestto-deliver (CTD) option in CDS contracts, which, in case of a credit event, allows the CDS holder to deliver the cheapest among all traded bonds to the protection seller. The value of this option is expected to raise the CDS' price, so that it should trade at a higher premium than the corresponding bond spread. This argument is also supported by De Wit (2006), who shows that technical constraints related to the difficulty of shorting corporate bonds can explain positive deviations in the basis. By studying co-integration of bond and CDS time series, De Wit (2006) affirms that prices may deviate slightly from fundamental values in the short run, but generally move in unison and converge to a long-run equilibrium.

The first thorough study of CDS-bond basis drivers is provided by Trapp (2009), who establishes a comovement between CDS prices and asset swap spreads using a vector error correction analysis. Trapp (2009) demonstrates that factors related to general market conditions and to firm liquidity and credit risk have a significant impact on basis levels. Nashikkar, Subrahmanyam and Mahanti (2011) propose a corporate bond liquidity measure that overcomes the problem of infrequent transaction prices and volumes in the bond market. They find that this liquidity measure has important explanatory power for the CDS-bond basis, exceeding that of other bond characteristics and traditional liquidity metrics such as observed trading volume. They also find that liquid bonds are more expensive than their corresponding CDS when compared with less liquid bonds.

The onset of the financial crisis challenged these earlier results. During the crisis, the basis reached unexpected and substantially negative levels that lasted several months, which is inconsistent with the cointegration feature observed during the previous period. Many researchers focused on this phenomenon in order to determine factors that explain these unusual levels. Fontana (2011) concentrates on the role of funding cost variables and argues that, during the financial crisis, the lack of funding sources, combined with a capital shortage due to huge losses incurred by market participants, impeded basis trading and, consequently, made convergence to equilibrium levels more difficult. Moreover, the increase in funding costs may have prevented basis traders from funding and maintaining their arbitrage positions 
and may have compelled them to close these positions by selling corporate bonds at a discount, which pulled the basis further down.

Similarly, Mitchell and Pulvino (2012) suggest that debt financing risk is one of the main causes of basis negativity. Hedge funds, which were among the most important players in the CDS-bond arbitrage operation, typically funded their activities through primary dealers. During the financial crisis, this activity was constrained by the inability of primary dealers to provide the needed capital and, as a result, the operation mechanism broke down. Garleanu and Pederson (2011) develop a theoretical generalequilibrium asset-pricing model that takes margin constraints into account. Applying their model to the CDS-bond basis, they conclude that deviations from equilibrium are caused by a difference in margin requirements of funded assets (such as corporate bonds) with respect to their unfunded derivatives (CDS). Bhanot and Guo (2012) examine the role of liquidity as a potential factor of basis deviation from parity. They distinguish two types of liquidity: arbitrageurs' funding liquidity and asset-specific liquidity. They find that the latter form of liquidity accounted for a considerable part of basis variability during the crisis. Augustin (2012) also emphasizes the importance of considering idiosyncratic, market, and funding liquidity risks separately. He concludes that, while all liquidity types have an impact on the magnitude of the basis variations, funding liquidity is the most relevant. In a more recent study, Bai and Collin-Dufresne (2019) explain the decline in the basis level by limits-to-arbitrage factors. They attribute the crosssectional variation of the basis during and after the financial crisis to risks and costs that were inherent to the arbitrage operation during that period. However, the authors do not provide a formal model to empirically isolate their arbitrage explanation. We complement their analysis of this issue.

Despite the puzzling fact that basis negativity persists long after the end of the financial crisis, very few studies focus on the post-crisis period. Kim, Li and Zhang (2017) do not study the basis determinants, but rather analyze the CDS-bond basis from a different angle, exploring the implications of arbitrage trades on corporate bonds' future returns. Using a regression model of the basis on the risk factors inherent to arbitrage activity, they split the basis into two parts. The first part is called the predicted basis and its variation is explained by risk factors, while the variations in the second residual part are not explained by variation in risk factors. These authors provide evidence that the residual part, which is exempt from all arbitrage risks, is a strong predictor of bond excess returns. Our main contribution is to extend their methodology to show explicitly how the limits to arbitrage explain the negative persistence of the CDSbond basis during the post-crisis period and to link this negative persistence to changes in the regulation of the financial markets. 
In conclusion, to the best of our knowledge, no empirical explanation has been provided for the lasting departure from equilibrium between the CDS and bond markets after the financial crisis. In that sense, our study complements the literature by focusing on a period spanning January 2006 to September 2014. In addition, we test an explanation for the persistence of a negative CDS-bond basis in the post-crisis era, starting in 2009. The role of post-crisis financial market regulation is also analyzed in detail.

\section{The CDS-Bond basis}

\subsection{Bond and CDS markets}

When buying a bond, an investor is exposed to the risk that the issuing corporation is unable to fulfill its legal commitment to pay the interest and/or the principal of the borrowed amount. A Credit Default Swap (CDS) is an instrument designed to short this credit risk. While related on several levels, the markets for CDSs and for their underlying bonds have different characteristics, specifically with respect to liquidity, investor types, and efficiency.

Unlike in the corporate bond market, where investors need to finance their position, CDS transactions do not involve much funding. Shorting credit risk is usually difficult in the bond market. The secondary bond market is not very liquid; investors generally hold bonds until maturity. This makes the CDS market interesting for investors who want to trade the credit risk of a reference entity, and explains the tremendous success of the CDS, which appeared as a liquid substitute to bonds for managing corporate credit risk. Over the last 20 years, the CDS market has become investors' preferred instrument to trade default risk, while the bond market remained less liquid and less popular. Some empirical studies provide evidence that CDS spreads have lower liquidity premium than corporate bonds (Cossin and Lu, 2005; Zhu, 2006; Kim, 2017). This difference should have affected the equilibrium basis during and after the financial crisis when liquidity risk became important.

The higher liquidity and lower funding costs associated with the CDS market, compared with the bond market, have a significant impact in the price discovery process. Indeed, informed traders prefer to trade on the more liquid and less costly CDS market, so that new market information is incorporated into CDS prices before bond prices (Blanco, Brennan and Marsh, 2005). As a result, the bond market's efficiency has been adversely affected by the introduction of the CDS instrument. The difference in efficiency and price discovery between the bond and CDS markets is also caused by a difference in their participants. 
Financial institutions, which are likely to be well informed, trade on both CDS and corporate bond markets, while uninformed retail investors are mainly active on the cash market.

The introduction of the CDS also had an impact on the bond-pricing mechanism. The CDS market allows investors to trade the CDS-bond basis. A negative basis trade consists of buying a CDS and holding a long position in the bond, which raises the bond price. In case of an economic downturn or of funding or liquidity difficulties, arbitrageurs may be unable to hold their portfolios and be forced to liquidate their position in both instruments, which may put downward pressure on bond prices. Kim, Li and Zhang (2017) provide empirical evidence that CDS-bond basis arbitrageurs' activity introduces sources of risk in the bond market, affecting bond returns.

\subsection{CDS-bond basis computation}

Duffie (1999) shows that the spread of a floating-rate note over a risk-free rate is equivalent to the price of a corresponding CDS with the same maturity. Accordingly, to accurately measure the CDS-bond basis, one would need to pick a floating-rate bond from among the firm's debt securities. Unfortunately, floating-rate bonds are much less commonly traded than fixed-rate bonds. While CDS prices are readily available, the way the bond spread is computed distinguishes various methods used to compute the basis, the three most common being the Z-spread, the Par Asset Swap Spread (ASW) and the Par Equivalent CDS Spread (PECDS).

The PECDS is the only method that explicitly considers default-risk factors, that is, the term structure of default probabilities and the recovery rate (Elizalde, Doctor and Saltuk, 2009; Nashikkar, Subrahmanyam and Mahanti, 2011). The PECDS is the premium of a synthetic CDS. Its default probability term structure allows the bond's discounted cash flows to be as close as possible to its observed price. The computation of the PECDS involves extracting the firm's default probability term structure from its corresponding CDS curve. This term structure is then shifted by a value minimizing the distance between the market price and the theoretical price of the bond. The last step consists of reversing the process by transforming the shifted default term structure into the premium of a synthetic CDS. The CDS-bond basis (Basis) is then the difference between the observed CDS premium (CDS) and the synthetic CDS premium (PECDS), so that

$$
\operatorname{Basis}_{i}(T)=\operatorname{CDS}_{i}(T)-\operatorname{PECDS}(T)
$$


where $i$ and $T$ index the reference entity and the maturity, respectively. Besides incorporating default characteristics, another advantage of the PECDS method is that it allows the comparison of different CDS values.

\subsection{Arbitrage}

\section{Limits to arbitrage}

In the specific case of credit derivatives, arbitrage opportunities arise when the prices in the CDS and bond markets diverge, so that the basis becomes positive or negative. The basis is positive when the bond spread is lower than its CDS premium. An appropriate arbitrage strategy is to short-sell the bond through a reverse repo and to sell the corresponding CDS contract. Conversely, a negative basis indicates that the bond spread is too high compared with its CDS premium. An arbitrageur can initiate a theoretically riskfree position by holding the bond and buying protection against its default. The arbitrageur thus hedges away the reference entity's default risk and simultaneously realizes a positive return equal to the basis value. Given that short selling a bond is generally more difficult than purchasing it, negative-basis trading is by far more popular among arbitrageurs than positive-basis trading.

Arbitrage is often defined as free money on the table. This perspective is challenged by Shleifer and Vishny (1997), who point out that noise traders can cause price deviations to widen, so that arbitrageurs may need to invest additional funds to maintain their positions. Given that keeping this capital flow for a long period is costly, especially for highly levered arbitrageurs, such a situation may cause their collapse. A well-known example is the collapse of the Long Term Capital Management (LTCM) hedge fund in 1998, where the managers were unable to fund their position and saw their capital destroyed in a few days, confirming that arbitrage activity indeed involves risks (Jorion, 2000; Dionne, 2019).

Since the LTCM demise, a growing body of literature has addressed limits to arbitrage that may deter arbitrageurs from correcting mispricing (Mitchell and Pulvino, 2012; Gromb and Vayanos, 2010; Brunnermeier and Pedersen, 2009). In practice, arbitraging away price distortions can be difficult, risky and costly; implementation costs and capital availability have been identified as the main issues hindering the ability to exploit price deviations. When funding is constrained and access to debt is limited, arbitrageurs may be unable to raise capital to implement or maintain an arbitrage position. Borrowing and transactions costs may also be so high that they exceed potential benefits, making arbitrage activity less attractive. In a nutshell, arbitrageurs are crucial for the effective functioning of financial markets, but 
various risks and costs weaken their ability and willingness to take advantage of price distortions, which allows these anomalies to persist.

\section{Negative-basis trading risks and costs}

In this section, we describe the negative CDS-bond basis trading steps thoroughly in order to identify the various limitations that may preclude this arbitrage activity and consequently hinder the price correction mechanism (Elizalde, Doctor and Saltuk, 2009).

As mentioned, a negative-basis arbitrage strategy involves purchasing a bond and buying protection on the CDS market. The bond purchase is often funded with borrowed money through the repo market, where the bond must be posted as collateral. The interest rate applied to this transaction is the repo rate, which varies across assets and may differ significantly from the risk-free rate, resulting in arbitrage costs. Repo transactions generally have short maturities, and extending the holding period requires rolling over the position, which may be executed at a higher repo rate. The rollover risk depends on both asset quality and capital availability. Typically, the bond's market value cannot be entirely borrowed through the repo market; the remaining haircut needs to be funded by other means. The size of the haircut depends on the credit and liquidity risks of the collateral: when the borrower's ability to sell the collateral is adversely affected, or when the bond is less valuable, the haircut increases. Accordingly, lower collateral quality on the repo market results in a higher haircut, which may reduce the profitability of the trade.

In contrast, taking a position on the CDS market requires an initial margin that is subject to margin calls, which are triggered when the credit quality of one of the two parties, i.e. the CDS seller or buyer, changes. Like haircuts, margin calls are typically financed at high interest rates. Thus, the ability of arbitrageurs to fund their position depends not only on the bond's quality, but also on funding liquidity, capital availability, and cost, which are subject to market conditions. Any worsening in funding conditions may reduce the arbitrageurs' return considerably. Even worse, during the financial crisis, the funding cost not only reached critical values, but funding itself became unavailable.

Empirical evidence shows that corporate bonds (Longstaff, Mithal and Neis, 2005) and their protections (Arakelyan and Serrano, 2016) are both subject to liquidity frictions that may hinder transactions and increase their cost. Moreover, arbitrageurs may need to unwind their position for some reason, such as the need for cash or to stop the loss caused by depreciation of their portfolio. The arbitrageurs then need to find investors eager to take the opposite position. This could be a particularly difficult, expensive and 
long process for an illiquid bond or CDS. This challenge can accentuate even further during a crisis period, when liquidity constraints are binding. Thus, arbitrageurs may find themselves stuck with a portfolio that is losing value every day, without being able to limit the damage and get rid of it. Therefore, liquidity specific to either a bond and/or a CDS can highly affect arbitrageurs' willingness to exploit price distortions.

Finally, the negative-basis arbitrage strategy is based on the assumption that, by holding both bond and CDS instruments, arbitrageurs are perfectly hedged against the reference entity's default risk, meaning that, in case of default, the CDS seller will undoubtedly compensate bond holders for their loss. However, this premise ignores counterparty risk in the CDS market, leaving arbitrageurs' long credit position uncovered. Simultaneous default of the instrument and of its protection can happen, and these two events can even exhibit positive correlation (wrong-way risk), particularly during financial crises.

These observations indicate that negative-basis trading is not a riskless operation. In practice, basis traders are subject to significant risks and costs, namely, funding costs, illiquidity on both the bond and CDS markets, protection sellers' counterparty risk, and bond collateral quality deterioration. Even if the arbitrageur can hedge the default risk through CDS protection, it is difficult, if not impossible, to eliminate all risks and costs inherent to negative-basis trading, which can therefore be considered to have its own risks and returns, like all other investment strategies.

\subsection{The post-crisis regulatory environment}

During the global financial crisis of 2007-2009, many financial institutions experienced liquidity, funding and solvency difficulties, causing significant losses and severely distressing the financial system. The crisis unveiled many shortcomings of the financial system's regulatory framework, and important changes in regulations and laws were introduced and gradually adopted during the post-crisis period.

A centerpiece of the regulatory reforms is the Basel III Accord, which aims at improving the liquidity and solvency of the banking system. This reform involves increased capital requirements for banks. Banks are required to hold more capital of higher quality against both their risky assets and their total exposure. Moreover, the Basel III reforms require banks to hold an adequate stock of liquid instruments and to limit funding risk by relying on stable, long-term sources of funding. Each of these restrictive reforms increases banks' capital cost and limits their role of providing liquidity to markets. 
Another important regulatory reform is the Volcker rule of the Dodd-Frank Wall Street Reform and Consumer Protection Act, which prohibits depository institutions from engaging in proprietary trading, except for market-making activities, and forbids banks from owning, investing in or sponsoring hedge funds and private equity funds.

While the aim of these regulatory reforms was to strengthen the health and resilience of the financial system, many market participants and researchers argue that these new regulations may have caused more harm than good (Bao, O'Hara and Zhou, 2018; Bessembinder, Jacobsen, Maxwell and Venkataraman, 2018). In fact, the higher capital and liquidity requirements, combined with new leverage ratios, reduced dealers' willingness to hold risky positions and, more importantly, increased their cost of capital. In particular, these requirements made funding through the repo market much more expensive. Duffie (2012) explains that market making is inherently a form of proprietary trading. The Volcker rule is thus blamed for reducing banks' market-making capacity and, consequently, for deteriorating liquidity provision in the corporate bond market (Dick-Nielsen and Rossi, 2017; Bao, O'Hara and Zhou, 2018).

The new regulatory framework therefore seems to be a hostile environment for CDS-bond basis arbitrageurs, who find it more difficult and costly to hedge their risks and manage their positions. To perform a negative-basis trade, arbitrageurs need to finance both bond and CDS purchases. To avoid huge losses, they must also be able to close their arbitrage position as soon as the basis starts to deteriorate. However, in an environment where market-making activity is hindered, liquidity is constrained, and capital cost is high, entering, holding or exiting the basis trade becomes difficult and expensive. This may dissuade market participants from engaging in basis arbitrage.

\section{Methodology and variables}

\subsection{Regime analysis}

One of our working hypotheses is that changes in the financial market environment may have altered the behavior of the CDS-bond basis. To better analyze the observation of an incomplete recovery from the non-zero basis anomaly after the crisis for all rating categories, we propose to investigate the evolution of the basis variable in a Markov switching-regime framework. We propose that changes in the basis level and variability are described by a Hidden Markov-switching Model (HMM) (Hamilton, 1990). We assume there are $n$ different regimes during our period of analysis. We apply the HMM model to the averaged 
basis monthly data and obtain the regime transition matrix along with the mean and variance of the basis variable in each of the $n$ regimes. We then check the robustness of the $n$-regime assumption by performing the same analysis with a $n+1$-regime model.

\subsection{Basis cross-sectional variation}

Further, we evaluate the impact of various frictions and constraints related to the negative-basis trade on the basis cross-sectional variations. Specifically, for each reference entity in our database we quantify arbitrage-risk variables, namely CDS and bond illiquidity, counterparty risk, collateral quality, and funding cost. We perform a multivariate Fama-Macbeth regression of the basis on these various sources of risk and cost according to the following equation:

$$
\mathrm{B}_{i t}=\alpha_{t}+\gamma_{1 \mathrm{t}} \mathrm{ILB} \mathrm{B}_{\mathrm{it}}+\gamma_{2 \mathrm{t}} \beta_{\mathrm{ILB}, \mathrm{i}}+\gamma_{3 \mathrm{t}} \mathrm{ILC} \mathrm{C}_{\mathrm{it}}+\gamma_{4 \mathrm{t}} \beta_{\mathrm{CNT}, \mathrm{i}}+\gamma_{5 t} \beta_{\mathrm{LB}, \mathrm{i}}+\gamma_{6 \mathrm{t}} \beta_{\mathrm{REP}, \mathrm{i}}+\gamma_{7 \mathrm{t}} \mathrm{RAT}_{\mathrm{it}}+\varepsilon_{\mathrm{it}}
$$

where $i$ and $t$ index the reference entity and the date respectively, and $B_{\text {it }}$ is a basis value observation. This regression is performed for each of the distinct Markov switching regimes identified by our HMM analysis. These periods are analyzed separately because of the considerable difference in market conditions during the different basis regimes. In addition, for robustness we also examine the impact of the risk factors on the basis within calendar periods of our sample with respect to the financial market crisis of 2008. Equation (2) differs from that of Bai and Collin-Dufresne (2019) in some respects. First, our periods of analysis are determined endogenously from the HMM model. Second, our definitions of some variables differ: in particular, we consider an illiquidity index for bonds (ILB) instead of three illiquidity variables, and we add an illiquidity variable for CDS (ILC).

These regressions are used to test, in each subperiod, whether variations in arbitrage risk and cost variables can explain the basis cross-sectional variation. If this were the case, that would indicate that negative-basis trading is risky, such that arbitrage risk and cost may prevent the CDS-bond basis of the more constrained arbitrage trades from converging to their fundamental levels.

Indeed, if risk-averse arbitrageurs had to choose between two trades on two different reference entities that have the same return but not the same exposure to funding risk, for example, they would choose the less risky trade. All risk-averse arbitrageurs would do the same, gradually reducing the return of the less risky trade and its basis until equilibrium is reached, while this correction mechanism would be absent for 
riskier arbitrage operations. We now define the variables used in Equation (2) and we concentrate our interpretation of their effect on the negative basis assumption.

\subsubsection{Bond illiquidity}

In a negative-basis trade, bond liquidity affects the market value of the arbitrage position and its variation, and, depending on market conditions, may affect trade attractiveness. In particular, liquidity constraints may prevent an arbitrageur from exiting a position. Two variables are used to describe bond illiquidity risk: ILB, which is a bond-illiquidity index based on eight different illiquidity measures, and $\beta_{\mathrm{ILB}}$, which represents the co-movement of specific and market illiquidity.

\section{Bond illiquidity risk}

Bond illiquidity risk is a multidimensional concept. There is no consensus on how to characterize it using a single measure. Consistent with Dick-Nielsen, Feldhutter and Lando (2012), we opt for a multidimensional methodology that consists of computing various illiquidity measures and performing a principal component analysis (PCA) in order to choose a single variable summarizing the pertinent information contained in these measures, which serves to construct our illiquidity index ILB. We use the eight distinct bond illiquidity measures described in the appendix. We indicate by $\mathrm{J}$ the number of illiquidity measures retained from the PCA analysis. We then create the illiquidity index ILB using these J measures. This index is defined by

$$
\mathrm{ILB}_{\mathrm{it}}=\sum_{\mathrm{j}=1}^{\mathrm{J}} \omega_{\mathrm{j}} \overline{\mathrm{V}}_{\mathrm{it}}^{\mathrm{j}}
$$

where $\bar{V}_{i t}^{j}$ is the normalized value of illiquidity measure $j$ and $\omega_{j}$ is its loading obtained from the PCA.

A bond's poor liquidity implies a higher illiquidity premium, which increases the bond spread and consequently pushes the basis toward negative values. Moreover, additional costs are borne by arbitrageurs when bond transactions are complicated by liquidity issues. Bond illiquidity should have an adverse impact on the negative-basis trade, and we therefore expect the coefficient of ILB to be negative in (2). 


\section{Bond illiquidity beta}

The bond illiquidity beta $\beta_{\text {Іьв }}$ contextualizes bond illiquidity by describing the dependence between the bond and market illiquidity (Acharya and Pedersen, 2005). In our application, market illiquidity, denoted by ILBM, is measured as the mean of the illiquidity variable ILB over the whole sample. $\beta_{\text {ILB }}$ is then defined as

$$
\beta_{\mathrm{ILB}, \mathrm{i}}=\frac{\operatorname{cov}\left(\mathrm{ILB}_{\mathrm{i}}, \mathrm{ILBM}\right)}{\operatorname{var}(\mathrm{ILBM})}
$$

When market conditions are poor and liquidity decreases, an arbitrageur intending to perform a negativebasis trade would choose the bond with illiquidity risk that is less correlated with market illiquidity. We expect that an increase in specific and market illiquidity dependence dissuades arbitrageurs from investing in a bond, which has an adverse impact on the negative-basis trade.

\subsubsection{CDS-liquidity risk}

To measure CDS illiquidity, we opt for one of the most used proxies in the literature (Coro, Dufour and Varotto, 2013), that is the bid-ask spread, denoted by ILC. Since negative-basis trading requires the arbitrageur to hold a long position in the CDS, illiquidity in this instrument should have an adverse impact on the investor's position and reduce the arbitrage return. In addition, CDS illiquidity can increase the cost and difficulty of closing the arbitrage position. All other things being equal, an arbitrageur choosing between two negative-basis trades would select the trade with the more liquid CDS, pushing its basis toward zero. Given that a more liquid CDS should be associated with a less negative basis, we expect the sign of the coefficient of ILC to be negative in (2).

\subsubsection{Counterparty risk}

Counterparty risk entails the possibility that both the bond and its protection seller default simultaneously. To characterize counterparty risk we evaluate the correlation between the reference entity and the CDS seller's stock returns. However, because the CDS market is over-the-counter (OTC), it is very difficult to accurately identify protection sellers. Accordingly, we identify CDS sellers by using the primary dealer market. The counterparty-risk variable is then defined by

$$
\beta_{\mathrm{CNT}, \mathrm{i}}=\frac{\operatorname{cov}\left(\mathrm{R}_{\mathrm{i}}, \mathrm{RD}\right)}{\operatorname{var}(\mathrm{RD})}
$$


where $R_{i}$ is the stock return of the reference entity and RD is the excess return of market primary dealers.

Through a CDS purchase, the arbitrageur seeks to partly eliminate negative basis trade risks, namely the firm's default risk. However, the worst scenario is when the protection provider becomes insolvent at nearly the same time as the bond's default. The CDS contract turns out to be worthless, which may deter the arbitrageur from investing in this trade and may consequently lower the basis. Therefore, the higher the counterparty risk, the less eager the market participants are to engage in basis trading, and the lower the negative basis level. We thus expect the coefficient of this variable to be negative in (2).

\subsubsection{Funding}

One of the major issues for any investor is funding. Arbitrageurs, which use borrowed money to finance their basis trades, are exposed to funding risk. One of the worst scenarios for arbitrageurs is when the basis is decreasing, which implies additional costs, simultaneously with a deterioration of funding conditions. Funding risk refers to the risk that the cost of borrowing to finance a negative-basis trade increases simultaneously with a decrease in the basis. Two variables, LIBOR beta $\left(\beta_{\text {LIB }}\right)$, and Repo spread beta $\left(\beta_{\text {REP }}\right)$ are used to characterize this risk.

\section{LIBOR beta}

This variable uses the difference between the LIBOR and OIS rates (LIB) as a proxy for the funding cost on the uncollateralized debt market. The variable $\beta_{\text {цв }}$ quantifies the dependence between the basis and uncollateralized funding cost variations, and is computed by

$$
\beta_{\mathrm{LB}, \mathrm{i}}=\frac{\operatorname{cov}\left(\text { basis }_{i}, \mathrm{LIB}\right)}{\operatorname{var}(\mathrm{LIB})}
$$

\section{Repo spread beta}

This variable uses the Repo spread, REP, that is the difference between the General Collateral repo rate and the Treasury Bill (T-Bill) rate. T-Bills are considered the safest bonds on the market. In case of adverse market conditions, investors prefer less risky investments, namely T-Bills, which would decrease their return compared with the repo rate. The variable REP is then a good indicator of the flight-to-quality 
phenomenon. The variable $\beta_{\text {REP }}$ captures the link between the basis and collateralized debt cost variations, and is computed by

$$
\beta_{\mathrm{REP}, \mathrm{i}}=\frac{\operatorname{cov}\left(\text { basis }_{i}, \mathrm{REP}\right)}{\operatorname{var}(\mathrm{REP})} .
$$

When basis variations are highly correlated with funding conditions, arbitrageurs could be subject to a sudden and important increase in trading costs, which they would have to fund at a higher price. Higher correlations thus deter arbitrageurs from investing in basis trades, which results in basis deterioration. Thus, the two funding variables are expected to have negative coefficients in (2).

\subsubsection{Collateral quality}

Similar to Bai and Collin-Dufresne (2019), we use Moody's ratings, which we convert into numbers where Aaa $=1, A A=2$ and so on, as a proxy of collateral quality denoted by RAT. ${ }^{1}$ While using ratings as a measure of bond creditworthiness can be criticized, in our case we are interested in the market's willingness to accept the bond as collateral and the resulting haircut, which is known to depend heavily on the bond's rating. On the repo market, a decrease in collateral quality results in a higher haircut and repo rate, which can reduce the arbitrage return significantly. All things being equal, arbitrageurs would then be more attracted by a basis trade with better collateral quality, resulting in a basis improvement. A negative sign is expected in (2).

Table 1 provides a list of the variables described above along with their symbol, definition and expected sign in regression (2).

[Table 1 about here]

\subsection{Residual and predicted basis analysis}

Prior to the financial crisis of 2008, a period with very little market frictions and few risks, arbitrageurs could lean against the negative basis until they made it disappear. Figure 1 clearly indicates that before the financial crisis, the CDS-bond basis was very close to zero, or slightly positive for high yield firms.

\footnotetext{
${ }^{1}$ In fact, Bai and Collin-Dufresne (2019) used CCC $=1$, CC- $=2, \ldots$ which explains the difference in the sign prediction for the parameter of RAT.
} 
[Figure 1 about here]

With the advent of the crisis, market conditions became difficult, as funding became rare and expensive and markets became illiquid. Consequently, arbitrage activities became difficult to execute, and the basis reached very negative values in the two bond categories, for a period of more than a year.

After the end of the turmoil, given the considerable improvement in financial market conditions, one would expect arbitrageurs to regain their ability to perform correcting trades, and consequently that the basis should return to its pre-crisis levels. However, contrary to expectations, CDS and bond spreads did not fully converge, as illustrated in Figure 1. Our main assumption is that the mechanism responsible for bringing the basis back to its fundamental value, i.e., negative-basis arbitrage, was not fully functional during the post-crisis period.

This assumption is motivated by growing concerns about the unintended negative impacts of the postcrisis regulations on financial markets, especially on liquidity provision, market making and cost of capital. Using a stylized example, Boyarchenko, Gupta, Steele and Yen (2016) show that the new capital regulations, in particular the supplementary leverage ratio, increased the cost of basis trading considerably. This results in a decrease in arbitrage profitability, which adversely affects arbitrageurs' incentives to initiate this type of trade. These arguments hint at lesser arbitrage activity, which would explain the persistence of basis negativity after the end of the crisis. In fact, at the current basis levels, arbitrageurs would have performed negative-basis trading in the pre-crisis period and would consequently have closed the existing gap between the two markets.

To show that the arbitrage mechanism is defective in the post-crisis period, causing the basis to constantly depart from equilibrium, we need a reliable measure for this activity. However, this is a challenging task because the identity of arbitrageurs is unknown, and arbitrage is not observable (Lou and Polk 2012).

To circumvent this problem, we opt for a methodology based on the separation of a variable into its predicted and residual components (Chen, Hribar and Melessa 2018). To do so, we exploit the results of regression (2). This regression aimed to show that CDS-bond basis arbitrage is not free money on the table, and that arbitrageurs face a wide range of constraints. If this were the case, then it is not realistic to consider that the entire basis is a pure gain for arbitrageurs. On the contrary, part of the basis would be compensation for arbitrage risks and costs, and only the portion that remains unexplained by the arbitrage 
risk and cost factors would represent the price discrepancy that arbitrageurs can correct through their arbitrage activity.

Accordingly, we divide the observed basis into two parts:

- The predicted basis, denoted PB, is the part of the basis explained by the arbitrage factors, namely funding, counterparty, value of collateral, and liquidity risks. This portion evaluates the reduction in return due to all the difficulties and frictions related to the basis trade.

- The residual basis, denoted RB, is the part of the basis exempt from the described risks and costs. This portion represents the real mispricing or, in other words, the real pure gain of an arbitrage trade. Although the residual basis may not be fully devoid of market frictions or risk factors that are not specified in our empirical model, it is expected to be less noisy in capturing mispricing after removing well-known risks and measurable market frictions (Kim, Li and Zhang 2016).

To show a decrease in the potency of arbitrage, we estimate, through different periods, the effect of this activity on two major aspects of the corporate bond market: purchase volume and pricing mechanism.

\subsection{Impact of basis arbitrage activity on bond purchase volume}

Assumption 1 The sensitivity of the bond purchase volume to the potential arbitrage gain decreased after the crisis.

Given that a negative-basis arbitrage strategy involves purchasing a bond and its CDS, then a larger potential profit, which is more appealing to arbitrageurs, will result in a larger amount of purchased bonds. In other words, extensive basis trading activity should influence transaction volumes significantly. This suggests that a regression of the amount of purchased bonds on the potential arbitrage gain, proxied by the residual basis, would have a positive coefficient.

In each period, we run multivariate cross-sectional regressions of the bond's purchase volume on the residual basis, controlling for the usual factors (Woodley 2010):

$$
\mathrm{BV}_{\mathrm{it}}=\alpha_{\mathrm{t}}+\gamma_{1 \mathrm{t}} \mathrm{RB}_{\mathrm{it}}+\sum_{\mathrm{k}=2}^{\mathrm{K}} \gamma_{\mathrm{kt}} \mathrm{C}_{\mathrm{kit}}+\varepsilon_{\mathrm{it}}
$$

where $i$ and $t$ index the reference entity and date respectively, BV is the bond purchased volume, and the variables $C_{k}$ are control variables. We use the coefficient $\gamma_{1}$, reflecting the sensitivity of bonds' trade volume to the potential pure arbitrage profit, as a proxy of the intensity of the negative-basis arbitrage 
activity. We expect the regression coefficient $\nu_{1}$, an indicator of the strength of the negative-basis trade activity, to be significantly positive before the crisis, reflecting a prevailing and efficient practice, while we expect $\gamma_{1}$ to be insignificant or small after the crisis, reflecting a dysfunction in the correction mechanism. The regressors used as control variables are the bond's one-day lagged purchased volume, age, amount outstanding, illiquidity measure, and rating on date $t$.

We focus our study on the bond market, instead of the CDS market, for three reasons. First, detailed daily data with buy/sell marks are available for bond transactions only. Second, before the CDS introduction and the initiation of basis arbitrage activity, the bond market was dominated by buy-and-hold investors, who were not very active. Third, given that basis deviations are generally small, arbitrageurs usually invest large amounts of money. Consequently, we believe that large transactions driven by arbitrage incentives should be easier to detect in the passive bond market than in the larger and more liquid CDS market.

\subsection{Impact of basis arbitrage activity on bond returns}

Assumption 2 The impact of arbitrage risks on bond returns decreased after the crisis.

During the financial crisis, difficult funding conditions compelled arbitrageurs to close their positions. This deleveraging phenomenon impacted the bond market by putting unusual pressure on bond prices, driving them down. Moreover, a decrease in negative-arbitrage activity reduces the demand for bonds. It is then logical to assume that the negative-basis arbitrage activity and, more specifically, risks related to this trade, may influence the bond-pricing mechanism. In fact, before the negative-basis trade became a popular activity, most of the bond market transactions were performed by passive buy-and-hold investors, who care about the risks described in Section 3.3 less than arbitrageurs do.

The predicted basis variable PB can be used as a proxy of the global risk involved in the negative-basis arbitrage trade, as in the study by Kim, Li and Zhang (2017). These authors use the predicted basis as the main explanatory variable to analyze the impact of negative-basis arbitrage on the price of corporate bonds. Using data from the pre-crisis period, they affirm an arbitraging channel through which the risks involved in negative-basis trades are transferred to bond returns and find that this channel exists only for investment-grade bonds. The authors explain this result by the fact that high yield bonds are rarely traded by arbitrageurs, so that negative-basis trade risks are not transferred to these bonds' returns. The arbitraging channel is thus nonexistent for this category of bonds. 
In the same way as for bond purchase volume, we study the relationship between arbitrage risks and bond returns in the post-crisis period in order to check whether it is still relevant. The goal is to support our assumption that arbitrage-trading activity decreased significantly after the crisis. If we show that risks linked to the basis trade, proxied by the predicted basis, are not affecting bond pricing as they did in the pre-crisis period, this means that the so-called arbitraging channel is destroyed or at least weakened, indicating a decrease in the basis-arbitrage force. To confirm this, we regress the bond excess returns during a 20-day holding period on the predicted basis:

$$
\mathrm{BR}_{\mathrm{it}}=\alpha_{\mathrm{t}}+\gamma_{2 \mathrm{t}} \mathrm{PB}_{\mathrm{it}}+\sum_{\mathrm{k}=2}^{\mathrm{K}} \gamma_{\mathrm{kt}} \mathrm{C}_{\mathrm{kit}}+\varepsilon_{\mathrm{it}}
$$

where $i$ and $t$ index the reference entity and the date respectively, BR is the bond's 20-day holding period excess return and $\mathrm{PB}$ is the predicted basis. The additional regressors $C_{k}$ used as control variables, are the bond's age, credit rating, coupon, illiquidity and issuance amount, defined as the par value of the debt initially issued.

A significant negative coefficient $\gamma_{2}$ indicates that the arbitrage risks, proxied by the predicted basis PB, negatively affect the bond returns $B R$, and that the arbitrage activity is functioning well. Conversely, a non-significant coefficient $\gamma_{2}$ indicates weak or nonexistent arbitrage activity. We expect the coefficient $\gamma_{2}$ to be a non-significant coefficient during the post-crisis period.

\subsection{Impact of basis arbitrage activity on the bond market during the post-crisis regulation period}

As mentioned in Section 3.4, there are serious suspicions that the new post-crisis regulations hampered arbitrageurs' activity and prevented them from bringing CDS and bond markets back to equilibrium (Boyarchenko, Gupta, Steele and Yen, 2016). However, directly relating the changes in arbitrageurs' behavior to the new regulatory framework is not an easy task (Dick-Nielsen, Feldhutter and Lando, 2012; Bessembinder, Jacobsen, Maxwell and Venkataraman, 2018; Bao, O'Hara and Zhou, 2018). We choose to approach this problem by comparing the impact of arbitrage trades on the bond market before and after each reform.

The two main regulatory changes we consider are the Dodd-Frank Act, which took effect in July 2010, and the implementation of the Basel III Accord in July 2013. We therefore divide the post-crisis period into three subperiods, according to the dates of the advent of these regulations, to check whether the impact 
of arbitrage activity on bonds' transaction volume and/or return was altered. We test the two following assumptions.

Assumption 3 The sensitivity of bond purchase volume to the potential arbitrage gain decreased after the introduction of the two new regulations.

Assumption 4 The impact of arbitrage risks on bond returns decreased after the introduction of the two new regulations.

\section{Data}

Our empirical investigation of the CDS-bond basis is based on a data sample that contains observations of 447 reference entities over the period 02/01/2006 to 30/09/2014, further divided into three sub-samples pertaining to three calendar subperiods related to the financial crisis (Saunders and Allen, 2016): pre-crisis $(02 / 01 / 2006$ to $30 / 06 / 2007)$, crisis (01/07/2007 to $31 / 03 / 2009)$ and post-crisis $(01 / 04 / 2009$ to 30/09/2014). These dates differ slightly from those of Bai and Collin-Dufresne (2019) regarding the enddate of the financial crisis (04/2009 instead of 09/2009). As we will see, this difference does not affect the results between the two studies. The analysis of our three calendar periods will be compared with that of the estimated Markov regime periods. Later, we will use these calendar periods to analyze the effects of regulation.

\subsection{CDS-bond basis}

\section{Data sources}

The first step in the construction of our database is the computation of the CDS-bond basis. We start by collecting CDS data from Markit Company, a reliable information provider for credit derivative instruments, which collects and aggregates quotes from principal market participants. We choose single name, senior CDS contracts with a Modified Structuring (MR) documentation clause and US dollar price. CDS premiums are quoted in basis points. We use CDS contracts with maturities ranging from 1 to 10 years for the construction of the default probability term structure of a given reference entity.

The next step is to match a 5-year-maturity CDS with its underlying bond, in order to be able to compare their spreads and compute the basis. Each reference entity has a set of issued bonds and only one CDS. Ideally, the CDS should be matched with the bond that appears on the protection contract, but this is not 
possible when dealing with a large sample. We choose instead the most classical bond with a maturity providing the best fit with the CDS MR clause.

Our first selection criterion is based on bond characteristics. We keep straight bonds only. We exclude securities denominated in foreign currencies or that have foreign issuer, variable coupons, or any special features such as put, call, conversion and exchange embedded options. We also exclude floating-rate bonds and bonds with sinking funds, in order to compute the bonds' discounted cash flows accurately. Our second criterion is maturity: since we need to compare the bond spread to a 5-year CDS premium, we select bonds with between 3 and 7.5 years left to maturity. The information on the criteria for selecting the bonds is obtained from the FISD (Fixed Investment Security Database).

Detailed bond transaction data are obtained from TRACE (Trade Reporting and Compliance Engine). For each selected bond, we extract the price, date, time and volume of every transaction. We use the DickNielson (2009) code to clean the TRACE database by removing transaction reporting errors.

Matching Trace and FISD data is relatively easy because bonds are identified by their CUSIP (Committee on Uniform Securities Identification) in both databases. This is not the case for Markit, where CDSs are identified by their RedCode, which needs to be matched with CUSIPs. To do so, we use two additional tables from Markit: the Entities XML file and the Obligations XML file. We use the LIBOR-swap curve downloaded from the Federal Reserve Board website for the risk-free rate used to discount cash flows in the PECDS computation.

\section{Summary statistics and preliminary analysis}

Table 2 provides summary statistics on the daily CDS-bond basis values, averaged across each calendar subperiod of the sample and across different rating categories. We observe that, prior to the financial market crisis, the theoretical well-established relationship between CDS and bond spreads is confirmed by the basis observed average level, which is close to zero. During the crisis, the average basis drops to 111 bps, with a significant increase in volatility. The average basis level during the post-crisis period is higher than during the crisis; post-crisis values are, however, still far from the pre-crisis level and volatility. Another striking observation is the pronounced cross-sectional differences in basis values between rating classes.

[Table 2 about here] 
Figure 1 depicts the evolution of the average CDS-bond basis of investment grade (IG) and high yield (HY) issuers over the three subperiods of the study. We observe that the dynamics of the basis for IG and HY bonds differ significantly over the entire period. Before the crisis, while the HY basis is slightly above zero, that of IG bonds is null; at the onset of the financial crisis, the decline in the basis is much more pronounced for HY than for IG bonds, with a minimum value of -800 bps for HY bonds at the height of the crisis, while the IG basis does not fall beyond -250 bps. Figure 1 also shows that the serious departure from equilibrium in credit risk markets for HY and IG firms becomes striking with the Lehman Brothers bankruptcy in September 2008. In the post-crisis period, the HY basis remains significantly lower than that of IG bonds, and significantly lower than the pre-crisis level. Basis volatility also differs across ratings: the basis of HY firms is much more volatile than that of IG firms, especially during the crisis period.

\subsection{Arbitrage risk and cost factors}

Risk factors are measured using a wide variety of data sources. Bond illiquidity proxies are computed using bond transaction data from TRACE. Correlation values for these proxies are presented in Table 3. As expected, some of the eight illiquidity measures are highly correlated. The results of the PCA used to construct the bond illiquidity variable are provided in Table 4. Based on these results, the first five illiquidity measures (Amihud, IRC, their variability, and Roll) and their loadings are retained to compute the bond illiquidity index.

\section{[Table 3 about here]}

[Table 4 about here]

The CDS illiquidity variable is computed from the bid-ask spread measure provided by two different data sources: CMA Datastream covers the period from 2006 to 2010, while the remaining values are obtained from Markit liquidity reports. To compute the counterparty risk variable, we use the value-weighted stock market returns, market capitalizations and equity returns obtained from CRSP. The list of primary dealers is downloaded from the Federal Reserve Bank of New York website.

The funding risk variables are computed using the Overnight Index Swap (OIS) and the 3-month general collateral repo rate, both obtained from Bloomberg. The correlation matrix of the variables used to measure the negative-basis arbitrage risk factors is presented in Table 5.

[Table 5 about here] 


\section{Empirical results}

\subsection{Regime analysis of the basis}

Table 6 reports the estimation results obtained using a three-regime Markov switching model for the monthly series of the average CDS-bond basis. ${ }^{2}$ We report the mean and standard deviation of the basis in each regime, along with the conditional probabilities of switching from one regime to another. All estimated values are highly significant. Figure 2 shows the monthly evolution of the basis over time, simultaneously with the endogenously defined basis Markov switching regimes, the subperiods used in our robustness analysis, and the Lehman bankruptcy date.

\section{[Table 6 about here]}

[Figure 2 about here]

According to our results, the third regime, where the basis variability and mean (in absolute value) are the highest, starts in the middle of the period that is commonly associated with the financial crisis. It is worth noting that this regime starts a few months before the peak of the crisis, corresponding to the Lehman Brothers bankruptcy, and lasts until almost one year after the official date associated with the end of the financial crisis, indicating the presence of a persistence aspect in basis regimes. In fact, our crisis period almost corresponds to the Crisis II period described by Bai and Collin-Dufresne (2019).

The first regime, identified with a slightly negative mean (-5.24 bps) and a low standard deviation (0.21 bps), covers the pre-crisis period and lasts until the first months of the financial crisis.

A second regime is identified by a significantly negative basis mean of -33.09 bps with a relatively low standard deviation of 1.52 bps. Surprisingly, the post-crisis regime, instead of showing a return to the normal (pre-crisis) period, shares the same second regime as the tumultuous first months of the financial crisis.

According to these observations, the period commonly identified with the financial crisis does not correspond to a single regime in the basis evolution, but rather to two distinct regimes, the second one persisting well beyond the recognized end of the financial crisis period. The persistent departure from

\footnotetext{
${ }^{2}$ We did reject the four-regime Markov model. Detailed results are available.
} 
equilibrium in the post-crisis period is thus confirmed by the endogenous basis dynamics. In the following sections, we will identify the second regime as a post-crisis regime, even though it contains months during and after the financial crisis.

\subsection{Basis cross-sectional variation}

Results of the multivariate Fama-Macbeth regression of the basis on arbitrage risk and cost measures, during the three Markov regimes, are summarized in Table 7.

[Table 7 about here]

The first factor of interest is bond illiquidity. As expected, the coefficient of the bond illiquidity variable ILB is significantly negative across the three subperiods. The highest impact of ILB on the basis is observed during the crisis subperiod (Regime 3), where the liquidity constraints in the corporate bond market were particularly severe (Dick-Nielsen, Feldhutter and Lando, 2012). Note that the impact of the ILB decreases after the crisis but remains significantly higher than in the pre-crisis subperiod. There is a growing and controversial body of literature that argues that regulatory changes following the financial crisis had an adverse impact on bond market liquidity (Anderson and Stulz, 2017; Bao et al., 2018), which, according to our results, further affects the negativity of the basis.

Second, we find that CDS illiquidity, as measured by the variable ILC, also plays an important role in explaining variations in the negative basis. The coefficient of ILC is significantly negative in all subperiods, indicating that the difficulty of executing negative-basis arbitrage trades when the CDS market is not liquid enough is a significant arbitrage-risk factor.

Our counterparty risk variable $\beta_{\mathrm{CNT}}$ reflects the risk of a simultaneous default of a reference entity and its protection seller. The coefficient of $\beta_{\mathrm{CNT}}$ has the expected negative sign in all subperiods. Interestingly, the impact of this variable is significantly lesser in the pre-crisis period. CDS sellers are large financial institutions with well-established reputations. Before the crisis, there was a general belief that these institutions were too solid to default. Arbitrageurs trusted them and, consequently, did not attribute much importance to their default risk, which was perceived to be low. This could explain the value of the coefficient of $\beta_{\mathrm{CNT}}$ in the pre-crisis period. However, during the crisis, firms that were believed to be too big to fail (e.g., Lehman Brothers) went bankrupt. Investors then became more aware of the importance of counterparty-default risk even when large institutions are involved. This is reflected in a considerable 
increase in the coefficient of $\beta_{\mathrm{CNT}}$ during the crisis period. Our results indicate that this loss of confidence persists during the post-crisis period (Regime 2), as reflected by a significantly negative coefficient, which is not as high as for the crisis period sample (Regime 3 ), but higher than its pre-crisis level.

Funding risk is captured by two variables, $\beta_{\mathrm{LB}}$ and $\beta_{\mathrm{REP}}$. They are related to the co-movements of the basis with funding conditions on the interbank and repo markets respectively. When the basis diverges, arbitrageurs face additional costs (marking to market, margin calls, etc.), which they finance with borrowed money. If this basis deterioration occurs simultaneously with a restriction on funding, arbitrage return decreases significantly. As a consequence, when basis variations are highly correlated with funding conditions, arbitrage trade becomes riskier, which may discourage arbitrageurs from investing in this activity. Our results indicate that interbank funding risk $\left(\beta_{\mathrm{LIB}}\right)$ has a negative impact on the basis during the post-crisis period while repo funding risk $\left(\beta_{\text {REP }}\right)$ has a negative impact during the crisis period, that is when capital became scarce and expensive (Gorton and Metrick, 2012).

Finally, the variable RAT, used as a proxy for bond collateral quality, has the expected significantly negative impact in all subperiods. The cost and the possibility to fund an arbitrage trade are closely related to the bond's collateral worthiness in the repo market, which is directly related to the repo rate, haircut and trade costs. Like for most variables, the impact of RAT on the negative basis is highest during the crisis period. Moreover, Gorton and Metrick (2012) document that repo haircuts increased dramatically during the financial crisis, to reach $50 \%$ in late 2008 , where many assets were no longer accepted as collateral.

In conclusion, our multivariate regressions explain much of the negative basis cross-sectional variation, with an $\mathrm{R}^{2}$ reaching $55 \%$ during the first regime. During the third regime, the explanatory power is $51 \%$ and almost all variables are significant and have the expected impact in this period. Moreover, our model also performs well during the second regime, with an $\mathrm{R}^{2}$ of $38 \%$ and many variables significant and having the intended impact.

As a robustness check, Table 8 reports the results of the multivariate Fama-Macbeth regression performed on three sub-samples constructed on the basis of the financial crisis calendar data often used in the literature to define the financial crisis period.

[Table 8 about here] 
Examination of Table 8 shows that the regression results are very similar to those obtained in Table 7. Indeed, during the various calendar periods, all the main risk factor coefficients are significant and have the expected sign. More importantly, we find that the impact of these factors on the basis is most pronounced during the tumultuous episode corresponding to the crisis regime. During the post-crisis regime, risk factors' effects decreased but remain highly significant and very different from those in the pre-crisis period.

To sum up, in the two tables, the bond (ILB) and CDS (ILC) illiquidity variables are highly negatively significant, as are the counterparty risk ( $\left.\beta_{\mathrm{CNT}}\right)$ and collateral quality (RAT) variables. These results strongly confirm our predictions and are consistent with those of Bai and Collin-Dufresne (2019). We now test why the equilibrium basis has not returned to zero after the financial crisis. We use the calendar periods of Table 8 for the analysis of the effect of regulatory changes on basis arbitrage activity during the post-crisis period.

\subsection{Residual and predicted basis analysis}

We now divide the basis variable observations into two components. From Equation (2), the residual basis (RB) is identified with pure arbitrage profit, while the predicted basis (PB) estimates the negative-arbitrage risks and costs. Table 9 reports the summary statistics pertaining to variables RB and PB over the entire study period. These statistics show that a large portion of the basis variation is explained by the various arbitrage-risk factors, such that the standard deviation of the residual basis is very small. Below we report the analyses of these two variables (RB and $\mathrm{PB}$ ) in order to test the assumptions supporting the argument that the persistence of a negative basis after the crisis is caused by a defect of the arbitrage mechanism.

\section{[Table 9 about here]}

\subsubsection{Impact of basis arbitrage activity on bond purchase volume}

Our first empirical analysis focuses on the impact that arbitrage activity should have on bond transaction volumes with respect to the passive buy-and-hold bond market. We want to show that after the crisis, an increase in the arbitrage pure potential gain, proxied by the residual basis, does not lead to an increase in the volume of bond trades, which is equivalent to saying that the coefficient $\gamma_{1}$ in regression (8) is not significant during the post-crisis period. 
The results of regression (8) performed to formally test Assumption 1 are presented in Table 11. We find that the coefficient $\gamma_{1}$ in Equation (8) is positive and significant in the pre-crisis period: a larger potential gain encourages arbitrageurs to invest and leads to an increase in bond purchases. This result confirms a well-established relationship between arbitrage trades and the bond market before the crisis, in the sense that arbitrage activity is well reflected in bond positions, and that more appealing negative basis trade results in an increase in traded bond amounts.

However, we find that coefficient $\gamma_{1}$ in Equation (8) is not significantly different from 0 during the crisis. Indeed, during this period, market conditions were difficult, with rare and expensive funding sources, liquidity problems and high counterparty risk, which prevented arbitrageurs from investing in negativebasis trades. This disruption in basis arbitraging activity is well captured by our regression.

We conclude this analysis by discussing the post-crisis period and compare the results with those of the pre-crisis period. Given that market conditions improved after the crisis, we expect arbitrage activity to resume and results to be comparable to those obtained for the pre-crisis period. This is, however, not the case, and the coefficient $\gamma_{1}$ is not significant in the post-crisis sample: an increase in potential profit, proxied by the residual basis, does not result in an increase in bond traded volume and in arbitrage activity.

[Table 11 about here]

\subsubsection{Impact of basis arbitrage activity on bond returns}

Our second argument is that arbitrage risk factors, which previously influenced bond prices through an arbitrage channel (Kim, Li and Zhang 2017), are no longer relevant during the post-crisis period. The results of regression (9) used to formally test Assumption 2 are summarized in Table 12.

[Table 12 about here]

We find that the impact of the predicted basis is significantly negative in the pre-crisis period. This result matches that of Kim, Li and Zhang (2017) and confirms their conclusion that arbitrage risk, as measured by the predicted basis, can predict future bond returns. A negative impact means that a more negative predicted basis, indicating riskier arbitrage trading, leads to higher compensation through higher future bond returns. These results show that arbitrage risks indeed affect the bond market, and that part of the arbitrage-risk premium is transferred to bond prices. 
However, this is no longer the case during the post-crisis period. The predicted basis coefficient $\gamma_{2}$ in Equation 9 is not significant. This means that risks involved in arbitrage trading do not affect bond returns during the post-crisis period. Therefore, arbitrage activity is not as important as it was in the pre-crisis period. If it were, the arbitraging channel would transmit basis risks into bond prices and the coefficient would be significant.

Empirical evidence supports our hypothesis of a decrease in arbitrage activity following the financial crisis of 2008 by showing that arbitrage forces no longer affect transaction volumes and the pricing mechanism in the corporate bond market. Consequently, when investors are no longer present in negative-basis trading, it is not surprising that the negative basis does not revert to its fundamental value.

\subsubsection{Impact of basis arbitrage activity on the bond market during the regulation era}

As seen in the two preceding sections, empirical results point to a defective arbitrage mechanism during the post-crisis period. We now investigate whether this defect can be attributed to changes in the regulatory environment, namely to the reforms advocated in the Dodd-Frank Act and in the Basel III Accord. We test assumptions 3 and 4 by examining the impact of the residual basis and of the predicted basis on bond purchase volumes and on bond returns in the post-crisis period, which we divide into three subperiods: before the regulatory reforms, after the passing of the Dodd-Frank Act, and after the implementation of Basel III.

Tables 13 and 14 report the regression results. Not surprising, the coefficients of the residual and of the predicted basis are both significant with the expected sign in the pre-regulation period. This result indicates that the relationship between arbitrage trading and corporate bond market trading volume and returns rebounded after the end of the financial crisis, suggesting that arbitrage activity resumed and impacted the cash market. However, this relationship is no longer detectable in the post-Dodd Frank Act period or in the post-Basel III period. One plausible conclusion is that, following a relative return to normal at the end of the financial crisis, the arbitrage mechanism became dysfunctional starting from the Dodd Frank Act reform date.

[Table 13 about here]

[Table 14 about here] 


\section{Conclusion}

This paper analyzes the behavior of the CDS-bond basis over a time period encompassing three distinct epochs, namely before, during, and after the recent global financial crisis, in order to explain the postcrisis persistent negativity of the basis.

We first show that the evolution of the basis over time allows us to identify three distinct Markov regimes. We find that the post-crisis level and the variability of the basis differ significantly from their corresponding values before the financial crisis, and that the regime for the post-crisis basis is similar to the regime prevailing during the first months of the financial crisis.

We then explore the cross-sectional variation of the CDS bond basis, with the aim of identifying the portion of the basis that represents pure arbitrage profit. To do so, we consider as explanatory variables the different risk and cost factors to which arbitrageurs involved in negative-basis trading are exposed. The way we express risk sources allows our model to explain much of the basis cross-sectional variation. We show that, over our entire period of study and not only during the financial crisis, a significant portion of the basis consists of compensation for the exposure to arbitrage risks and costs. We also verify that bond and CDS liquidity risk, bond collateral and CDS counterparty risk have significant power to explain the variations in the basis, particularly during the crisis and post-crisis periods.

Finally, we test that the puzzling persistence of a negative basis after the crisis is caused by a dysfunction in the correction mechanism of the market, namely, arbitrage activity. We use an indirect approach to empirically document the decrease in arbitrage activity by tracing its impact on the bond market. We find that the relationship between arbitrage profitability and bond purchases, and between arbitrage risk and bond prices, is no longer significant in the post-crisis period, pointing to dysfunctional arbitrage activity that causes a constant disequilibrium situation between CDS and bond spreads. We also find that the deterioration in arbitrage activity is concurrent with the post-crisis regulatory reforms. 


\section{References}

Acharya, V., Pedersen, L.H. (2005). Asset pricing and liquidity risk. Journal of Financial Economics, 77, 375410.

Adrian, T., Fleming, M.J., Shachar, O. (2017). Market liquidity after the financial crisis. Federal Reserve Bank of New York, Liberty Street Economics. https://libertystreeteconomics.newyorkfed.org/2017/ 06/market-liquidity-after-the-financial-crisis.html.

Alexander, G., Sharpe, W. (1990). Investments. Englewood Cliffs, NJ: Prentice Hall.

Anderson, M., Stulz, R.M. (2017). Is post-crisis bond liquidity lower? Working paper 23317, NBER, Boston.

Arakelyan, A., Serrano, P. (2016). Credit spread changes within switching regimes. Journal of Multinational Financial Management, 37-38, 139-157.

Augustin, P. (2012). Squeezed everywhere: Can we learn something new from the CDS-Bond Basis? Working paper, McGill University.

Bai, J., Collin-Dufresne, P. (2019). The CDS-Bond basis. Financial Management, 48, 417-439.

Bao, J., O'Hara, M., Zhou, XA. (2018). The Volcker rule and market-making in times of stress. Journal of Financial Economics, 1-19.

Bessembinder, H., Jacobsen, S., Maxwell, W., Venkataraman, K. (2018). Capital commitment and illiquidity in corporate bonds. Journal of Finance, LXXIII, 4, 1615-1661.

Bhanot, K., Guo, L. (2012). Types of liquidity and limits to arbitrage-the case of credit default swaps. Journal of Futures Markets, 32, 4, 301-329.

Blanco, R., Brennan, S., Marsh, I. (2005). An empirical analysis of the dynamic relation between investment-grade bonds and Credit Default Swaps. Journal of Finance, 60, 2255-2281.

Boyarchenko, P., Gupta, P., Steele, N., Yen, Y. (2016). Trends in credit market arbitrage. Federal Reserve Bank of New York Staff Reports, 784.

Brunnermeier, M., Pederson, LH. (2009). Market liquidity and funding liquidity. Review of Financial Studies, 22,6, 2201-2238.

Chen, W., Hribar, P., Melessa, S. (2018). Incorrect inferences when using residuals as dependent variables. Journal of Accounting Research, 56,3, 751-796.

Coro, F., Dufour, A., Varotto, S. (2013). Credit and liquidity components of corporate CDS spreads. Journal of Banking and Finance, 37, 5511-5525.

Cossin, D., Lu, H. (2005). Are European corporate bonds and default swap markets segmented? Working Paper, International Center for Financial Asset Management and Engineering.

De Wit, J. (2006). Exploring the CDS-bond basis. Working Paper 104, National Bank of Belgium.

Dick-Nielsen, J. (2009). Liquidity biases in TRACE. Journal of Fixed Income, 19, 2, 43-55.

Dick-Nielsen, J., Feldhutter, P., Lando, D. (2012). Corporate bond liquidity before and after the onset of the subprime crisis. Journal of Financial Economics, 103, 3, 471-492.

Dick-Nielsen, J., Rossi, M. (2017). The cost of immediacy for corporate bonds. Working paper, Texas A\&M University.

Dimson, E., Mussavian, M. (2000). Three centuries of asset pricing. Journal of Banking and Finance, 23, $12,1745-1769$.

Dionne, G. (2019). Corporate Risk Management: Theories and Applications. Wiley Finance Series, 404 pages. 
Dionne, G., Maalaoui Chun, O. (2013). Default and liquidity regimes in the bond market during the 20022012 period. Canadian Journal Economics, 46, 4, 1160-1195.

Duffie, D. (1999). Credit swap valuation. Financial Analysts Journal, 55,1, 73-87.

Duffie, D. (2012). Market-making under the proposed Volcker rule. Working Paper, Stanford University.

Elizalde, A., Doctor, S., Saltuk, Y. (2009). Bond-CDS basis handbook. J.P.Morgan Credit Derivatives Research.

Fama, E.F. (1970). Efficient capital markets: A review of theory and empirical work. Journal of Finance, 25, 2, 383-417.

Feldhütter, P. (2012). The same bond at different prices: Identifying search frictions and selling pressures. Review of Financial Studies, 25, 4, 1155-1206.

Fontana, A. (2011). The negative CDS-bond basis and convergence trading during the 2007/09 financial crisis. Swiss Finance Institute Research paper no 11-41.

Garleanu, N., Pedersen, LH. (2011) Margin-based asset pricing and deviations from the law of one price. Review of Financial Studies, 24, 6, 1980-2022.

Gorton, G., Metrick, A. (2012). Securitized banking and the run on repo. Journal of Financial Economics, 104, 425-451.

Gromb, D., Vayanos, D. (2010). Limits of arbitrage. Annual Review of Financial Economics, 2, 251-275.

Grossman, S.J., Stiglitz, J.E. (1980). Types of liquidity and limits to arbitrage-the case of credit default swaps. The American Economic Review, 70, 3, 393-408.

Hamilton, JD. (1990). Analysis of time series subject to changes in regime. Journal of Econometrics, 45, 12, 39-70.

Jorion, P. (2000). Risk management lessons from long-term capital management. European Financial Management, 6, 277-300.

Kim, G.H., Li, H., Zhang, W. (2016). CDS-bond basis and bond return predictability. Journal of Empirical Finance, 38, 307-337.

Kim, G.H., Li, H., Zhang, W. (2017). The CDS-bond basis arbitrage and the cross section of corporate bond returns. Journal of Future Markets, 37, 8, 836-861.

Kim, K. (2017). Liquidity basis between credit default swap and corporate bonds markets. International Review of Economics and Finance, 48, 98-115.

Kryukova, M., Copeland, L. (2015). The CDS-bond basis puzzle in the financial sector. Cardiff Economics, Working paper.

Longstaff, F.A., Mithal, S., Neis, E. (2005). Corporate yield spreads: Default risk or liquidity? New evidence from the Credit Default Swap market. Journal of Finance, 60, 5, 2213-2254.

Lou, D., Polk, C. (2012). Comomentum: Inferring arbitrage activity from return correlations. Working paper, London School of Economics.

Mitchell, M.L., Pulvino, T.C. (2012). Arbitrage crashes and the speed of capital. Journal of Financial Economics, 104, 3, 469-490.

Nashikkar, A., Subrahmanyam, M.G., Mahanti, S. (2011). Liquidity and arbitrage in the market for credit risk. Journal of Financial and Quantitative Analysis, 88, 272-298.

Roll, R. (1984). A simple implicit measure of the effective bid-ask spread in an efficient market. Journal of Finance, 39, 1127-1139.

Saunders, A., Allen, L. (2010). Credit Risk: Measurement In and Out of the Financial Crisis. Wiley Finance, 380 pages. 
Shleifer, A., Vishny, R.W. (1997). The limits of arbitrage. Journal of Finance, 52, 35-55.

Trapp, M. (2009). Trading the bond-CDS basis - The role of credit risk and liquidity. Working Paper 09-16, Center for Financial Research, University of Cologne.

Woodley, M. (2010). The cross section of trading activity in the over-the-counter market for corporate bonds. Journal of Trading, 5, 2, 78-91.

Zhu, H. (2006). An empirical comparison of credit spreads between the bond market and the credit default swap market. Journal of Financial Services Research, 29, 211--235. 


\section{Appendix: Illiquidity measures}

1. Amihud measure (AMI): Defined as the ratio of the absolute average daily return over the daily trading volume, this measure characterizes the daily price impact of trades, that is, how much prices move following a given trade volume. The Amihud measure increases with the sensitivity of prices to transaction volumes, and indicates illiquidity. The Amihud measure for a reference entity $i$ at date $t$ is computed by

$$
A M I_{i t}=\left(\frac{1}{N_{i t}}\right) \sum_{j=1}^{N_{i t}}\left(\frac{1}{Q_{j t}^{i}}\right) \frac{P_{j t}^{i}-P_{j-1, t}^{i} \mid}{P_{j-1, t}^{i}},
$$

where $N_{i t}$ is the number of transactions on date $t$ and $Q_{j t}^{i}$ and $P_{j t}^{i}$ are, respectively, the volume and price of transaction $\mathrm{j}=1, \ldots, \mathrm{N}_{\mathrm{it}}$. Liquidity increases with transaction numbers and volumes and decreases with price differentials.

2. Imputed Roudtrip Cost (IRC): This measure, proposed by Feldhütter (2012), is computed by

$$
I R C=\frac{P_{\text {Max }}-P_{\text {Min }}}{P_{\text {Max }}},
$$

where $\mathrm{P}_{\mathrm{Max}}$ and $\mathrm{P}_{\mathrm{Min}}$ are the maximum and minimum prices of an Imputed Roundtrip Trade, observed when, on a given day, a bond trades $n$ times with the same volume. This is likely to be a trade between a buyer, a seller and a dealer, so that the difference between the minimum and maximum prices reflects the bid-ask spread retained by the dealer.

3. Amihud variability $\left(\sigma_{\mathrm{AMI}}\right)$ : the standard deviation of a daily Amihud illiquidity measure over a 21-day moving window. The variability of a bond illiquidity measure indicates the range of its possible future levels.

4. IRC variability $\left(\sigma_{\mathrm{IRC}}\right)$ : the standard deviation of daily IRC over a 21-day moving window.

5. Roll measure (ROL): As shown by Roll (1984), under certain assumptions it is possible to infer bonds' bid-ask spread from consecutive transaction prices, according to the following formula:

$$
\mathrm{ROL}_{\mathrm{it}}=2 \sqrt{-\operatorname{cov}\left(\Delta_{\mathrm{it}}, \Delta_{\mathrm{i}, \mathrm{t}-1}\right)}
$$


where $\Delta_{i t}$ is a series of differences between transaction prices. The Roll measure is computed on a daily basis using a 21-day moving window, with at least four transactions in each window. The rationale behind this measure is that transaction prices alternate between bid and ask levels, so that a higher bid-ask spread leads to a higher (negative) covariance between successive prices.

6. Bond holding time (BHT): The average holding time of a bond can be expressed as the inverse of turnover, that is, the ratio of the amount outstanding over total trading volume. The higher the bond holding time, the more illiquid the bond.

7. Bond zero-trading days (B0): This variable measures the proportion of days where the bond is not traded during a given period; it is computed over a rolling window of 21 days. A higher ratio reflects a more illiquid bond.

8. Firm zero-trading days (F0): This variable measures the proportion of days where none of the bonds issued by the firm are traded during a period of 21 days. 
Table 1: List of variables

This table provides the list of variables, symbols, definitions, data sources along with the predicted sign for the regression coefficient.

\begin{tabular}{|c|c|c|c|c|}
\hline Variable & Symbol & Definition & Data source & $\begin{array}{l}\text { Predicted sign for the } \\
\text { regression coefficient }\end{array}$ \\
\hline Bond illiquidity & ILB & $\begin{array}{l}\text { Linear combination of bond illiquidity } \\
\text { proxies obtained from a PCA analysis }\end{array}$ & Trace & Negative \\
\hline Bond illiquidity beta & $\beta_{\text {ILB }}$ & $\begin{array}{l}\text { Dependence between the bond and } \\
\text { market illiquidity }\end{array}$ & Trace & Negative \\
\hline CDS illiquidity & ILC & CDS bid-ask spread & Markit & Negative \\
\hline Counterparty risk & $\beta_{\mathrm{CNT}}$ & $\begin{array}{l}\text { Dependence between the reference } \\
\text { entity and the primary dealers' stock } \\
\text { return }\end{array}$ & CRSP, Federal Reserve Bank of New York & Negative \\
\hline LIBOR beta & $\beta_{\mathrm{LIB}}$ & $\begin{array}{l}\text { Dependence between the basis and the } \\
\text { LIBOR-OIS }\end{array}$ & $\begin{array}{l}\text { Federal Reserve Bank of New York, } \\
\text { Bloomberg }\end{array}$ & Negative \\
\hline Repo spread beta & $\beta_{\text {REP }}$ & $\begin{array}{l}\text { Dependence between the basis and the } \\
\text { Repo spread }\end{array}$ & $\begin{array}{l}\text { Federal Reserve Bank of New York, } \\
\text { Bloomberg }\end{array}$ & Negative \\
\hline Collateral quality & RAT & Reference entity's rating & FISD & Negative \\
\hline
\end{tabular}


Table 2: Basis summary statistics

This table provides summary statistics for the CDS-bond basis in basis points for different Moody's rating categories during three periods: pre-crisis period (02/01/2006 to 30/06/2007), financial crisis period (01/07/2007 to 31/03/2009) and post-crisis period (01/04/2009 to 30/09/2014).

\begin{tabular}{|c|c|c|c|c|c|c|c|c|c|c|c|c|}
\hline & \multicolumn{4}{|c|}{ Pre-crisis } & \multicolumn{4}{|c|}{ Crisis } & \multicolumn{4}{|c|}{ Post-crisis } \\
\hline & Mean & S.D. & Min & Max & Mean & S.D. & Min & Max & Mean & S.D. & Min & Max \\
\hline All & -5.56 & 3.17 & -15.53 & 1.79 & -110.82 & 113.65 & -372.66 & 3.53 & -45.04 & 38.20 & -233.94 & 3.98 \\
\hline IG & -6.71 & 2.19 & -15.53 & -2.12 & -78.26 & 70.67 & -231.46 & -0.61 & -29.39 & 24.14 & -146.40 & 3.98 \\
\hline HY & -0.44 & 10.51 & -32.62 & 32.92 & -202.70 & 248.54 & -792.61 & 31.50 & -93.61 & 83.74 & -535.29 & -16.99 \\
\hline $\mathrm{AAA} / \mathrm{AA}$ & -3.23 & 1.93 & -11.51 & 0.67 & -20.20 & 30.80 & -115.19 & 28.74 & -5.06 & 7.18 & -24.31 & 29.36 \\
\hline A & -4.87 & 2.07 & -14.08 & -0.85 & -56.72 & 50.33 & -184.28 & 8.62 & -18.29 & 17.86 & -105.49 & 3.98 \\
\hline BBB & -11.53 & 3.34 & -29.41 & -4.36 & -143.75 & 111.31 & -365.65 & -4.55 & -42.90 & 37.23 & -234.53 & -9.04 \\
\hline BB & -8.84 & 8.96 & -36.43 & 22.38 & -171.20 & 178.28 & -633.00 & 24.52 & -81.89 & 55.38 & -355.10 & -5.50 \\
\hline B & 4.75 & 16.04 & -29.76 & 43.28 & -161.14 & 246.60 & -641.64 & 58.46 & -62.92 & 54.52 & -387.85 & 4.32 \\
\hline $\mathrm{CCC}$ & -8.52 & 57.11 & -186.49 & 66.30 & -272.94 & 242.89 & -761.49 & 37.60 & -166.10 & 146.15 & -680.47 & 4.15 \\
\hline
\end{tabular}


Table 3: Correlation matrix of the illiquidity variables

This table provides correlation values for the eight corporate bond liquidity measures. These measures are computed daily for the period 02/01/2006 to 30/09/2014. Bond transaction data are obtained from TRACE and bond information is obtained from FISD. The definitions of the variables are in the appendix.

\begin{tabular}{lllllllll}
\hline & AMI & $\sigma_{\text {AMI }}$ & IRC & $\sigma_{\text {IRC }}$ & ROL & BHT & BO & F0 \\
\hline AMI & 1 & & & & & & & \\
$\sigma_{\text {AMI }}$ & 0.54 & 1 & & & & & & \\
IRC & 0.49 & 0.26 & 1 & & & & & \\
$\sigma_{\text {IRC }}$ & 0.37 & 0.45 & 0.50 & 1 & & & & \\
ROL & 0.30 & 0.37 & 0.38 & 0.44 & 1 & & & \\
BHT & 0.26 & 0.16 & 0.02 & 0.05 & 0.05 & 1 & & \\
BO & -0.19 & -0.11 & -0.13 & -0.06 & 0.08 & 0.14 & 1 & \\
F0 & -0.16 & -0.10 & -0.13 & -0.07 & 0.05 & 0.13 & 0.85 & 1 \\
\hline
\end{tabular}

Table 4: Results of the Principal Component Analysis (PCA) for the liquidity measures

This table provides the CPA loadings for each of the eight corporate bond liquidity measures and the cumulative explanatory contribution of the components. The measures are computed daily for the period 02/01/2006 to 30/09/2014. The bond transaction data are obtained from TRACE and bond information from FISD. The definitions of the variables are in the appendix. PCi is for principal component $i$.

\begin{tabular}{|c|c|c|c|c|c|c|c|c|}
\hline & PC1 & PC2 & PC3 & PC4 & PC5 & PC6 & PC7 & PC8 \\
\hline AMI & 0.41 & 0.09 & 0.41 & 0.24 & 0.49 & 0.27 & -0.51 & 0.02 \\
\hline$\sigma_{\mathrm{AMI}}$ & 0.42 & 0.17 & -0.02 & -0.46 & 0.50 & -0.12 & 0.55 & 0.12 \\
\hline IRC & 0.37 & 0.01 & 0.03 & 0.75 & -0.18 & -0.13 & 0.46 & 0.01 \\
\hline$\sigma_{\mathrm{IRC}}$ & 0.44 & 0.19 & -0.28 & -0.11 & -0.23 & -0.63 & -0.45 & -0.01 \\
\hline ROL & 0.37 & 0.26 & -0.36 & -0.16 & -0.38 & 0.69 & -0.02 & -0.03 \\
\hline BHT & 0.08 & 0.21 & 0.78 & -0.28 & -0.49 & -0.06 & 0.09 & -0.01 \\
\hline BO & -0.26 & 0.63 & -0.05 & 0.09 & 0.07 & -0.01 & -0.01 & 0.70 \\
\hline F0 & -0.27 & 0.63 & -0.02 & 0.11 & 0.12 & -0.04 & -0.01 & -0.70 \\
\hline $\begin{array}{l}\text { Cum. } \\
\text { explained }\end{array}$ & $30 \%$ & $51 \%$ & $64 \%$ & $75 \%$ & $84 \%$ & $91 \%$ & $97 \%$ & $100 \%$ \\
\hline
\end{tabular}


Table 5: Correlation matrix of the negative basis arbitrage risk factors

This table provides the correlation matrix of arbitrage risk factor variables for three distinct calendar subperiods. Panel A pertains to the pre-crisis period (02/01/2006 to 30/06/2007), Panel B to the crisis period (01/07/2007 to 31/03/2009), and Panel $C$ to the post-crisis period (01/04/2009 to 30/09/2014). Definitions of the variables are in Table 1.

\begin{tabular}{|c|c|c|c|c|c|c|c|}
\hline \multicolumn{8}{|c|}{ Panel A: Pre-Crisis } \\
\hline & ILB & $\beta_{\mathrm{ILB}}$ & ILC & $\beta_{\mathrm{CNT}}$ & $\beta_{\mathrm{LIB}}$ & $\beta_{\text {REP }}$ & RAT \\
\hline ILB & 1.0000 & & & & & & \\
\hline$\beta_{\mathrm{ILB}}$ & 0.1478 & 1.0000 & & & & & \\
\hline ILC & 0.0494 & 0.0558 & 1.000 & & & & \\
\hline$\beta_{\mathrm{CNT}}$ & -0.0095 & -0.1254 & -0.3562 & 1.0000 & & & \\
\hline$\beta_{\mathrm{LIB}}$ & 0.1121 & -0.0039 & 0.1133 & -0.0035 & 1.0000 & & \\
\hline$\beta_{\text {REP }}$ & -0.0934 & 0.0353 & -0.1459 & 0.0205 & -0.8784 & 1.0000 & \\
\hline RAT & 0.0225 & 0.0963 & 0.6228 & -0.5554 & 0.2140 & -0.2135 & 1.0000 \\
\hline \multicolumn{8}{|c|}{ Panel B: Crisis } \\
\hline & ILB & $\beta_{\text {ILB }}$ & ILC & $\beta_{\mathrm{CNT}}$ & $\beta_{\text {LIB }}$ & $\beta_{\text {REP }}$ & RAT \\
\hline ILB & 1.0000 & & & & & & \\
\hline$\beta_{\text {ILB }}$ & 0.3245 & 1.0000 & & & & & \\
\hline ILC & 0.1139 & 0.0478 & 1.0000 & & & & \\
\hline$\beta_{\mathrm{CNT}}$ & 0.2172 & 0.3776 & -0.0138 & 1.0000 & & & \\
\hline$\beta_{\mathrm{LIB}}$ & -0.1296 & -0.1716 & -0.1120 & -0.1582 & 1.0000 & & \\
\hline$\beta_{\text {REP }}$ & 0.0596 & 0.0825 & 0.0607 & 0.0311 & -0.8710 & 1.0000 & \\
\hline RAT & 0.0627 & -0.0841 & 0.2014 & -0.4027 & -0.1719 & 0.1371 & 1.0000 \\
\hline \multicolumn{8}{|c|}{ Panel C: Post-Crisis } \\
\hline & ILB & $\beta_{\mathrm{ILB}}$ & ILC & $\beta_{\mathrm{CNT}}$ & $\beta_{\text {LIB }}$ & $\beta_{\text {REP }}$ & RAT \\
\hline ILB & 1.0000 & & & & & & \\
\hline$\beta_{\text {ILB }}$ & 0.2735 & 1.0000 & & & & & \\
\hline ILC & 0.0352 & -0.0099 & 1.0000 & & & & \\
\hline$\beta_{\mathrm{CNT}}$ & 0.0817 & 0.2241 & -0.0152 & 1.0000 & & & \\
\hline$\beta_{\mathrm{LIB}}$ & -0.1433 & -0.1185 & -0.0042 & -0.0482 & 1.0000 & & \\
\hline$\beta_{\text {REP }}$ & -0.2449 & -0.2216 & -0.0212 & -0.1410 & 0.2973 & 1.0000 & \\
\hline RAT & 0.1712 & 0.0190 & 0.0743 & -0.0557 & -0.0811 & -0.2097 & 1.0000 \\
\hline
\end{tabular}


Table 6: Basis Markov switching-regime parameters

Panel A provides the basis switching-regime model parameters. We report the mean and standard deviation of the basis, along with their $p$-values in each regime. Panel B provides the conditional probabilities $p_{i j}$ of the switching process from Regime $R_{i}$ to Regime $R_{j}$.

\begin{tabular}{|c|c|c|c|}
\hline Panel A & & & \\
\hline & $\mathrm{R} 1$ & $\mathrm{R} 2$ & R3 \\
\hline Mean & -5.24 & -33.09 & -219.39 \\
\hline$p$-value & 0.00 & 0.00 & 0.00 \\
\hline Standard_dev & 0.21 & 1.52 & 123.79 \\
\hline$p$-value & 0.00 & 0.00 & 0.00 \\
\hline \multicolumn{4}{|l|}{ Panel B } \\
\hline & $\mathrm{R} 1$ & $\mathrm{R} 2$ & R3 \\
\hline R1 & 0.84 & 0.01 & 0.16 \\
\hline $\mathrm{R} 2$ & 0.16 & 0.96 & 0.00 \\
\hline R3 & 0.00 & 0.03 & 0.84 \\
\hline Log_Likelihood & & -446.71 & \\
\hline
\end{tabular}


Table 7: Multivariate Fama-MacBeth regressions for the whole sample during basis endogenous regimes

This table provides the results of the multivariate cross-sectional Fama-Macbeth regressions of the negative CDS-bond basis on bond and CDS illiquidity, counterparty risk, collateral quality, and funding risk factors. We report the mean coefficients, standard errors, and R-squared values. Results are provided for three periods that correspond to the three endogenous basis regimes: Regime 1 (02/01/2006 to $31 / 10 / 2007)$, Regime $2(01 / 11 / 2007$ to $31 / 07 / 2008$ and 16/12/2009 to 30/09/2014), and Regime 3 $(01 / 08 / 2008$ to $15 / 12 / 2009)$. The cross-sectional regressions run at daily frequency. ${ }^{*}, *$, and $* * *$ denote significance at the $10 \%, 5 \%$, and $1 \%$ levels, respectively. Definitions of the variables are in Table 1.

\begin{tabular}{|c|c|c|c|}
\hline Variable & $\begin{array}{c}\text { Regime } 1 \text { (pre-crisis) } \\
02 / 01 / 2006 \text { to } 31 / 10 / 2007\end{array}$ & $\begin{array}{c}\text { Regime } 2 \text { (post-crisis) } \\
01 / 11 / 2007 \text { to } 31 / 07 / 2008 \& \\
16 / 12 / 2009 \text { to } 30 / 09 / 2014\end{array}$ & $\begin{array}{c}\text { Regime } 3 \text { (crisis) } \\
01 / 08 / 2008 \text { to } 15 / 12 / 2009\end{array}$ \\
\hline $\begin{array}{l}\text { Bond illiquidity } \\
\text { (ILB) }\end{array}$ & $\begin{array}{l}-1.48^{* * *} \\
(0.11)\end{array}$ & $\begin{array}{l}-1.63^{* * *} \\
(0.07)\end{array}$ & $\begin{array}{l}-9.82^{* * *} \\
(0.51)\end{array}$ \\
\hline $\begin{array}{l}\text { Bond illiquidity beta } \\
\left(\beta_{\text {ILB }}\right)\end{array}$ & $\begin{array}{l}-0.42^{* *} \\
(0.20)\end{array}$ & $\begin{array}{l}2.88^{* * *} \\
(0.26)\end{array}$ & $\begin{array}{l}-1.35 \\
(2.09)\end{array}$ \\
\hline $\begin{array}{l}\text { CDS illiquidity } \\
\text { (ILC) }\end{array}$ & $\begin{array}{l}-0.10^{* * *} \\
(0.02)\end{array}$ & $\begin{array}{l}-0.08^{* * *} \\
(0.01)\end{array}$ & $\begin{array}{l}-0.07^{* * *} \\
(0.01)\end{array}$ \\
\hline $\begin{array}{l}\text { Counterparty risk } \\
\left(\beta_{\mathrm{CNT}}\right)\end{array}$ & $\begin{array}{l}-3.90 * * * \\
(0.63)\end{array}$ & $\begin{array}{l}-6.91 * * * \\
(0.57)\end{array}$ & $\begin{array}{l}-98.38^{* * *} \\
(5.12)\end{array}$ \\
\hline $\begin{array}{l}\text { Libor beta } \\
\left(\beta_{\mathrm{LIB}}\right)\end{array}$ & $\begin{array}{l}0.19 * * * \\
(0.06)\end{array}$ & $\begin{array}{l}-0.01 * * * \\
(0.01)\end{array}$ & $\begin{array}{l}0.06^{* * *} \\
(0.01)\end{array}$ \\
\hline $\begin{array}{l}\text { Repo spread beta } \\
\left(\beta_{\text {REP }}\right)\end{array}$ & $\begin{array}{l}0.16^{* * *} \\
(0.04)\end{array}$ & $\begin{array}{l}0.002^{* * *} \\
(0.01)\end{array}$ & $\begin{array}{l}-0.13^{* *} \\
(0.02)\end{array}$ \\
\hline $\begin{array}{l}\text { Collateral quality } \\
\text { (RAT) }\end{array}$ & $\begin{array}{l}-1.54 * * * \\
(0.16)\end{array}$ & $\begin{array}{l}-7.20 * * * \\
(0.09)\end{array}$ & $\begin{array}{l}-25.78^{* * *} \\
(1.04)\end{array}$ \\
\hline Constant & $\begin{array}{l}3.54^{* *} \\
(1.44)\end{array}$ & $\begin{array}{l}23.08^{* * *} \\
(0.71)\end{array}$ & $\begin{array}{l}169.41^{* * *} \\
(9.39)\end{array}$ \\
\hline$R^{2}$ & 0.55 & 0.38 & 0.51 \\
\hline
\end{tabular}


Table 8: Multivariate Fama-MacBeth regressions for the whole sample during pre-crisis, crisis and post-crisis periods

This table provides the results of the multivariate cross-sectional Fama-Macbeth regressions of the negative CDS-bond basis on bond and CDS illiquidity, counterparty risk, collateral quality and funding risk factors. We report the mean coefficients, standard errors, and R-squared values. Results are provided for three periods that correspond to the three calendar periods: pre-crisis $(02 / 01 / 2006$ to $30 / 06 / 2007)$, crisis (01/07/2007 to 31/03/2009), and post-crisis (01/04/2009 to 30/09/2014). The cross-sectional regressions run at daily frequency. ${ }^{*}, *$, and $* * *$ denote significance at the $10 \%, 5 \%$, and $1 \%$ levels, respectively. Definitions of the variables are in Table 1.

\begin{tabular}{|c|c|c|c|}
\hline Variable & $\begin{array}{c}\text { Pre-crisis } \\
02 / 01 / 2006 \text { to } 30 / 06 / 2007\end{array}$ & $\begin{array}{c}\text { Crisis } \\
(01 / 07 / 2007 \text { to } 31 / 03 / 2009)\end{array}$ & $\begin{array}{c}\text { Post-crisis } \\
01 / 04 / 2009 \text { to } 30 / 09 / 2014\end{array}$ \\
\hline $\begin{array}{l}\text { Bond illiquidity } \\
\text { (ILB) }\end{array}$ & $\begin{array}{l}-1.38^{* * *} \\
(0.12)\end{array}$ & $\begin{array}{l}-6.12^{* * *} \\
(0.92)\end{array}$ & $\begin{array}{l}-2.27^{* * *} \\
(0.26)\end{array}$ \\
\hline $\begin{array}{l}\text { Bond illiquidity beta } \\
\left(\beta_{\mathrm{ILB}}\right)\end{array}$ & $\begin{array}{l}-0.55^{* * *} \\
(0.20)\end{array}$ & $\begin{array}{l}-0.68 \\
(1.81)\end{array}$ & $\begin{array}{l}2.80^{* * *} \\
(0.70)\end{array}$ \\
\hline $\begin{array}{l}\text { CDS illiquidity } \\
\text { (ILC) }\end{array}$ & $\begin{array}{l}-0.12^{* * *} \\
(0.02)\end{array}$ & $\begin{array}{l}-0.05^{* * *} \\
(0.02)\end{array}$ & $\begin{array}{l}-0.08^{* * *} \\
(0.01)\end{array}$ \\
\hline $\begin{array}{l}\text { Counterparty risk } \\
\left(\beta_{\mathrm{CNT}}\right)\end{array}$ & $\begin{array}{l}-4.10^{* * *} \\
(0.74)\end{array}$ & $\begin{array}{l}-68.90^{* * *} \\
(12.55)\end{array}$ & $\begin{array}{l}-9.83 * * * \\
(2.02)\end{array}$ \\
\hline $\begin{array}{l}\text { Libor beta } \\
\left(\beta_{\mathrm{LIB}}\right)\end{array}$ & $\begin{array}{l}0.24 * * * \\
(0.07)\end{array}$ & $\begin{array}{l}0.08^{* * *} \\
(0.03)\end{array}$ & $\begin{array}{l}-0.02 * * * \\
(0.01)\end{array}$ \\
\hline $\begin{array}{l}\text { Repo spread beta } \\
\left(\beta_{\text {REP }}\right)\end{array}$ & $\begin{array}{l}0.20^{* * *} \\
(0.05)\end{array}$ & $\begin{array}{l}0.10^{* *} \\
(0.05)\end{array}$ & $\begin{array}{l}0.01 * * * \\
(0.01)\end{array}$ \\
\hline $\begin{array}{l}\text { Collateral quality } \\
\text { (RAT) }\end{array}$ & $\begin{array}{l}-1.23 * * * \\
(0.14)\end{array}$ & $\begin{array}{l}-14.60^{* * *} \\
(2.20)\end{array}$ & $\begin{array}{l}-9.24 * * * \\
(0.67)\end{array}$ \\
\hline Constant & $\begin{array}{l}4.20^{* *} \\
(0.14)\end{array}$ & $\begin{array}{l}90.72^{* * *} \\
(18.19)\end{array}$ & $\begin{array}{l}36.78^{* * *} \\
(5.32)\end{array}$ \\
\hline $\mathrm{R}^{2}$ & 0.55 & 0.48 & 0.38 \\
\hline
\end{tabular}


Table 9: Summary statistics of predicted and residual basis

This table provides summary statistics for the CDS-bond basis, predicted basis and residual basis in basis points for the period 02/01/2006 to 30/09/2014. The predicted basis PB is the portion of the basis explained by the arbitrage risk factors using regression (2). The residual basis $\mathrm{RB}$ is the remaining portion of the basis.

\begin{tabular}{lrrrr}
\hline & Mean & Std. dev. & Min & Max \\
\hline Basis & -82.52 & 80.93 & -780.90 & -7.21 \\
PB & -82.52 & 80.93 & -780.91 & -7.21 \\
RB & 0.00 & 0.01 & -0.14 & 0.53 \\
\hline
\end{tabular}

Table 10: Bond purchase volume grouped according to the value of the residual basis

This table provides the mean volume of purchased bonds for each of four observations sets. Portfolios 1 to 4 pool the bonds according to the value of the residual basis. Results are provided for the three periods: pre-crisis (02/01/2006 to 30/06/2007), crisis (01/07/2007 to 31/03/2009), and post-crisis (01/04/2009 to 30/09/2014). Transaction data are obtained from TRACE.

\begin{tabular}{lccc}
\hline Variable & $\begin{array}{c}\text { Pre-crisis } \\
\text { 02/01/2006 to 30/06/2007 }\end{array}$ & $\begin{array}{c}\text { Crisis } \\
\text { (01/07/2007 to 31/03/2009) }\end{array}$ & $\begin{array}{c}\text { Post-crisis } \\
01 / 04 / 2009 \text { to 30/09/2014 }\end{array}$ \\
\hline $\begin{array}{l}\text { Portfolio1 } \\
\text { (lowest RB) }\end{array}$ & $1,384,410$ & $1,906,511$ & $1,415,079$ \\
Portfolio2 & $1,648,443$ & $1,664,319$ & $1,374,388$ \\
Portfolio3 & $1,730,442$ & $1,440,176$ & $1,389,248$ \\
Portfolio4 & $1,810,907$ & $1,482,073$ & $1,556,415$ \\
(Highest RB) & & & \\
\hline
\end{tabular}


Table 11: Multivariate Fama-MacBeth regressions of the purchased bond volume on the residual basis

This table reports the results of the daily cross-sectional regression of the bond purchase volume on the residual basis and a set of control variables. The residual basis is the portion that is unexplained by the arbitrage risk factors in Equation (1). Control variables are: the bond's lagged volume, age, amount outstanding, Moody's rating (RAT) and illiquidity factor (ILB). Results are provided for the three periods: pre-crisis (02/01/2006 to 30/06/2007), crisis (01/07/2007 to $31 / 03 / 2009)$, and post-crisis (01/04/2009 to $30 / 09 / 2014) . *, * *$, and $* * *$ denote significance at the $10 \%, 5 \%$, and $1 \%$ levels, respectively.

\begin{tabular}{|c|c|c|c|}
\hline Variable & $\begin{array}{c}\text { Pre-crisis } \\
02 / 01 / 2006 \text { to } 30 / 06 / 2007\end{array}$ & $\begin{array}{c}\text { Crisis } \\
\text { (01/07/2007 to } 31 / 03 / 2009)\end{array}$ & $\begin{array}{c}\text { Post-crisis } \\
01 / 04 / 2009 \text { to } 30 / 09 / 2014\end{array}$ \\
\hline Residual basis & $\begin{array}{c}0.60 * * \\
(0.23)\end{array}$ & $\begin{array}{l}-0.10 \\
(0.08)\end{array}$ & $\begin{array}{l}-0.00 \\
(0.01)\end{array}$ \\
\hline Lagged volume & $\begin{array}{l}0.10 * * * \\
(0.02)\end{array}$ & $\begin{array}{l}0.12^{* * * *} \\
(0.01)\end{array}$ & $\begin{array}{l}0.14^{* * * *} \\
(0.00)\end{array}$ \\
\hline Age & $\begin{array}{l}-0.31 * * * \\
(0.04)\end{array}$ & $\begin{array}{l}-0.34^{* * *} \\
(0.03)\end{array}$ & $\begin{array}{l}-0.20 * * * \\
(0.01)\end{array}$ \\
\hline $\begin{array}{l}\text { Amount } \\
\text { outstanding }\end{array}$ & $\begin{array}{l}0.93 * * * \\
(0.07)\end{array}$ & $\begin{array}{l}1.37 * * * \\
(0.07)\end{array}$ & $\begin{array}{l}1.12 * * * \\
(0.02)\end{array}$ \\
\hline ILB & $\begin{array}{l}-0.11^{* * *} \\
(0.01)\end{array}$ & $\begin{array}{l}-0.08 * * * \\
(0.00)\end{array}$ & $\begin{array}{l}-0.10 * * * \\
(0.00)\end{array}$ \\
\hline RAT & $\begin{array}{l}0.16^{* * *} \\
(0.01)\end{array}$ & $\begin{array}{l}0.14^{* * *} \\
(0.00)\end{array}$ & $\begin{array}{l}0.15^{* * *} \\
(0.00)\end{array}$ \\
\hline Constant & $\begin{array}{l}-0.15 \\
(0.16)\end{array}$ & $\begin{array}{l}-0.30 \\
(0.12)\end{array}$ & $\begin{array}{l}-0.94 \\
(0.04)\end{array}$ \\
\hline $\mathrm{R}^{2}$ & 0.19 & 0.16 & 0.15 \\
\hline
\end{tabular}


Table 12: Multivariate Fama-MacBeth regressions of bond returns on predicted basis

This table reports the results of the daily cross-sectional regression of the future bond returns over a 20day horizon, on the predicted basis and a set of control variables. The predicted basis is the portion of the basis explained by the arbitrage risk factors in Equation (1). Control variables are the bond's Moody's rating (RAT), age, annual coupon, issuance amount and illiquidity factor (ILB). Results are provided for the three periods: pre-crisis (02/01/2006 to 30/06/2007), crisis (01/07/2007 to 31/03/2009), and post-crisis $(01 / 04 / 2009$ to $30 / 09 / 2014) . *{ }^{* *}$, and $* * *$ denote significance at the $10 \%, 5 \%$, and $1 \%$ levels, respectively.

\begin{tabular}{lccc}
\hline Variable & Pre-crisis & Crisis & Post-crisis \\
& $02 / 01 / 2006$ to $30 / 06 / 2007$ & $(01 / 07 / 2007$ to $31 / 03 / 2009)$ & $01 / 04 / 2009$ to $30 / 09 / 2014$ \\
\hline Predicted basis & $-0.96^{* *}$ & 0.34 & -0.09 \\
\multirow{2}{*}{ RAT } & $(0.26)$ & $(0.29)$ & $(0.16)$ \\
& 0.08 & -3.56 & $5.71^{* * *}$ \\
Age & $(0.85)$ & $(2.94)$ & $(0.85)$ \\
& 0.02 & $-0.09 * *$ & -0.00 \\
Coupon & $(0.03)$ & $(0.04)$ & $(0.00)$ \\
& -0.33 & $1.2 * * *$ & $-0.20^{* * *}$ \\
Issuance_amount & $(0.21)$ & $(0.43)$ & $(0.08)$ \\
& -0.02 & $-0.08^{*}$ & $-0.06^{* * *}$ \\
ILB & $(0.02)$ & $(0.04)$ & $(0.01)$ \\
& $3.72 * * *$ & $4.09 * * *$ & $4.90^{* * *}$ \\
Constant & $(1.08)$ & $(1.49)$ & $(0.43)$ \\
& 0.78 & 0.35 & $0.23^{* * *}$ \\
$\mathrm{R}^{2}$ & $(0.11)$ & $(0.27)$ & $(0.07)$ \\
\hline
\end{tabular}


Table 13: Multivariate Fama-MacBeth regressions of bond purchase volume on the residual basis during the post-crisis period

This table reports the results of the daily cross-sectional regression of bond purchase volume on the residual basis and a set of control variables. The residual basis is the portion that is unexplained by the arbitrage risk factors in Equation (1). Control variables are: the bond's lagged volume, age, amount outstanding, Moody's rating (RAT) and illiquidity factor (ILB). Results are provided for three periods: after the crisis but before the Dodd-Frank Act (01/04/2009 to 20/07/2010), after the Dodd-Frank Act (21/07/2010 to 30/06/2014), and after the Basel III reform (01/07/2013 to 30/09/2014). *, **, and *** denote significance at the $10 \%, 5 \%$, and $1 \%$ levels, respectively.

\begin{tabular}{lccc}
\hline Variable & $\begin{array}{c}\text { Before Dodd-Frank } \\
02 / 01 / 2006 \text { to } 30 / 06 / 2007\end{array}$ & $\begin{array}{c}\text { After Dodd -Frank } \\
(01 / 07 / 2007 \text { to } 31 / 03 / 2009)\end{array}$ & $\begin{array}{c}\text { After Basel III } \\
01 / 04 / 2009 \text { to } 30 / 09 / 2014\end{array}$ \\
\hline Residual basis & $0.10^{* *}$ & 0.05 & -0.02 \\
Lagged volume & $(0.03)$ & $(0.03)$ & $(0.05)$ \\
& $0.15^{* * *}$ & $0.13^{* * *}$ & $0.13^{* * *}$ \\
Age & $(0.01)$ & $(0.01)$ & $(0.01)$ \\
& $-0.19^{* * *}$ & $-0.21^{* * *}$ & $-0.21^{* * *}$ \\
Amount & $(0.01)$ & $(0.02)$ & $(0.14)$ \\
outstanding & $1.53^{* * *}$ & $1.02^{* * *}$ & $0.94^{* * *}$ \\
ILB & $(0.06)$ & $(0.04)$ & $(0.04)$ \\
& $-0.11^{* * *}$ & $-0.11^{* * *}$ & $-0.09^{* * *}$ \\
RAT & $(0.01)$ & $(0.00)$ & $(0.00)$ \\
& $0.19^{* * *}$ & $0.14^{* * *}$ & $0.12^{* * *}$ \\
Constant & $(0.09)$ & $(0.00)$ & $(0.00)$ \\
& $-1.24^{* * *}$ & $-0.89^{* * *}$ & $-0.71^{* * *}$ \\
$\mathrm{R}^{2}$ & $(0.16)$ & $(0.12)$ & $(0.08)$ \\
\hline
\end{tabular}


Table 14: Multivariate Fama-MacBeth regressions of bond returns on predicted basis during the post-crisis period

This table reports the results of the daily cross-sectional regression of the future bond returns over a 20day horizon, on the predicted basis and a set of control variables. The predicted basis is the portion of the basis explained by the arbitrage risk factors in Equation (1). Control variables are the bond's Moody's rating (RAT), age, annual coupon, issuance amount and illiquidity factor (ILB). Results are provided for three periods: after the crisis but before the Dodd-Frank act (01/04/2009 to 20/07/2010), after the DoddFrank act was passed (21/07/2010 to 30/06/2014), and after the Basel III reform (01/07/2013 to $30 / 09 / 2014) . *{ }^{* *}$, and ${ }^{* * *}$ denote significance at the $10 \%, 5 \%$, and $1 \%$ levels, respectively.

\begin{tabular}{lccc}
\hline Variable & $\begin{array}{c}\text { Pre-crisis } \\
\text { 02/01/2006 to } 30 / 06 / 2007\end{array}$ & $\begin{array}{c}\text { Crisis } \\
(01 / 07 / 2007 \text { to } 31 / 03 / 2009)\end{array}$ & $\begin{array}{c}\text { Post-crisis } \\
01 / 04 / 2009 \text { to } 30 / 09 / 2014\end{array}$ \\
\hline Predicted basis & $-0.71^{* * *}$ & 0.20 & -0.07 \\
RAT & $(0.13)$ & $(0.17)$ & $(1.26)$ \\
& $5.53^{* *}$ & $-7.32^{* * *}$ & 1.50 \\
Age & $(2.70)$ & $(1.69)$ & $(0.95)$ \\
& 0.03 & -0.02 & -0.01 \\
Coupon & $(0.02)$ & $(0.01)$ & $(1.17)$ \\
& $-0.51^{*}$ & 0.09 & -0.08 \\
Issuance_amount & $(0.27)$ & $(0.11)$ & $(0.05)$ \\
& -0.09 & $-0.06^{*}$ & $-0.02^{* * *}$ \\
ILB & $(0.03)$ & $(0.04)$ & $(0.01)$ \\
& $5.12^{* * *}$ & $4.46^{* * *}$ & $6.03^{* * *}$ \\
Constant & $(1.14)$ & $(0.90)$ & $(0.56)$ \\
& $0.44^{* * *}$ & 0.06 & $0.39^{* * *}$ \\
$\mathrm{R}^{2}$ & $(0.21)$ & $(0.15)$ & $(0.07)$ \\
\hline
\end{tabular}


Figure 1: The CDS-bond basis of IG and HY firms

This figure plots the two-week time series of the CDS-bond basis' mean value for two groups of firms according to their Moody's rating: investment grade (IG) and high yield (HY), from 02-01-2006 to 30-09-2014.

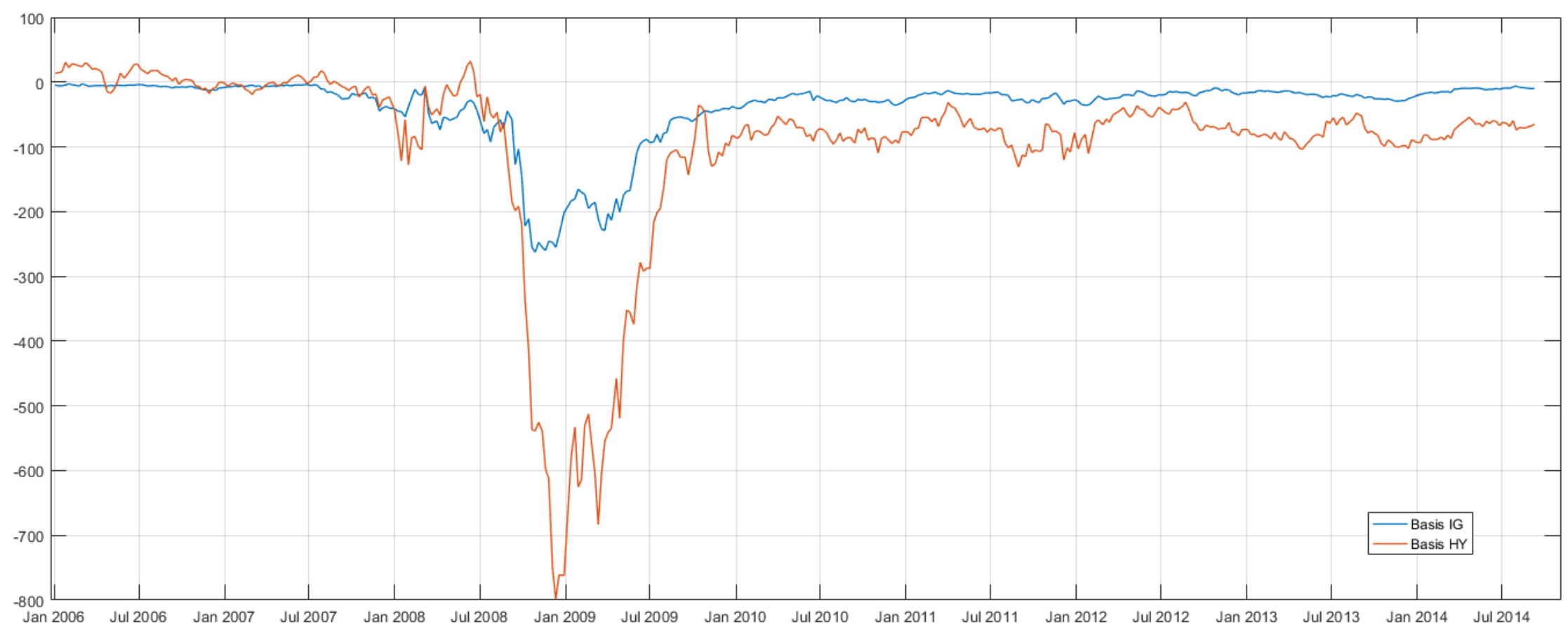


Figure 2: Basis switching regimes, financial crisis period and Lehman Brothers collapse date

The figure plots the monthly average basis, the three regimes identified by the Markov switching model, the financial crisis period and the Lehman Brothers bankruptcy date.

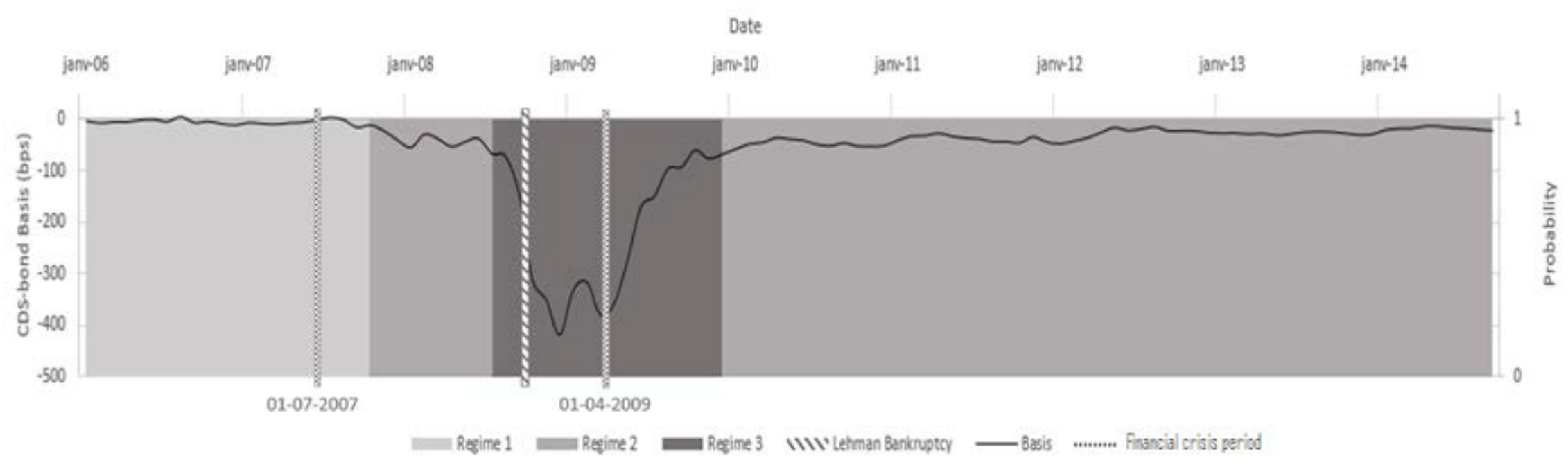

